\author{
UNIVERSIDADE DE SÃO PAULO \\ ESCOLA DE ENFERMAGEM DE RIBEIRÃO PRETO
}

\title{
USO DE ADOÇANTES E ALIMENTOS DIETÉTICOS POR PESSOAS DIABÉTICAS
}

GISELE DE SOUSA

Ribeirão Preto

2006 


\title{
UNIVERSIDADE DE SÃO PAULO \\ ESCOLA DE ENFERMAGEM DE RIBEIRÃO PRETO
}

\section{USO DE ADOÇANTES E ALIMENTOS DIETÉTICOS POR PESSOAS DIABÉTICAS}

\section{GISELE DE SOUSA}

\begin{abstract}
Dissertação apresentada à Escola de Enfermagem de Ribeirão Preto da Universidade de São Paulo, para obtenção do Título de Mestre em Enfermagem Geral e Especializada, inserida na linha de pesquisa: Processo de cuidar do adulto com doenças agudas e crônicodegenerativas.
\end{abstract}

Orientadora: Prof $^{\mathrm{a}}$ Dr $^{\mathrm{a}}$ Maria Lúcia Zanetti

Ribeirão Preto

2006 


\section{FICHA CATALOGRÁFICA}

\begin{tabular}{|l|}
\hline Sousa, Gisele \\
Uso de adoçantes e alimentos dietéticos por pessoas diabéticas. \\
Ribeirão Preto, 2006. \\
64 p. : il. ; 30cm \\
Dissertação de Mestrado, apresentada à Escola de Enfermagem de \\
Ribeirão Preto/USP - Área de concentração: Enfermagem Fundamental. \\
Orientadora: Zanetti, Maria Lúcia. \\
1. Diabetes mellitus. 2. Adoçantes dietéticos. 3. Alimentos \\
dietéticos.
\end{tabular}


Data da Dissertação:

\section{Banca Examinadora}

Prof $^{a}$ Dr $^{\mathrm{a}}$ Maria Lúcia Zanetti

Julgamento:

Assinatura:

Prof $^{a} \operatorname{Dr}^{\mathrm{a}}$ Rosane Pilot Pessa Ribeiro

Julgamento:

Assinatura:

$\operatorname{Prof}^{\circ} \operatorname{Dr}^{0}$ Manoel Antonio dos Santos

Julgamento: Assinatura: 


\section{DEDICATÓRIA}

Dedico as minhas companheiras Mãe e Avó,

Minha mãe porque sonhou muito comigo a realização deste trabalho. Obrigada pelo incentivo, força e pelas orações.

E a minha avó, que apesar dos oitenta anos de idade ainda faz tudo por mim e para mim.

Amo vocês ! 


\section{AGRADECIMENTOS}

\section{Prof $^{\mathrm{a}}$ Dr $^{\mathrm{a}}$ Maria Lúcia Zanetti}

Agradeço por ter trabalhado comigo, para que esse sonho se tornasse realidade. Sua experiência com pessoas diabéticas me ajudou bastante no desenvolvimento deste estudo. Admiro muito você e obrigada por tudo.

\section{Prof $^{\text {a }}$ Dr $^{\text {a }}$ Rosane Pilot Pessa Ribeiro}

Seu olhar de colega de profissão e suas sugestões foram imprescindíveis para o aperfeiçoamento deste trabalho. Obrigada.

\section{Prof $^{\circ}$ Dr $^{\circ}$ Manoel Antonio dos Santos}

Agradeço pela oportunidade de tê-lo em minha banca, contribuindo brilhantemente com seus conhecimentos e experiência.

\section{Prof ${ }^{\circ}$ Vanderlei José Hass}

Pela importante colaboração e disponibilidade sempre que precisei.

\section{As nutricionistas da Nutrition Care}

Obrigada pela oportunidade de trabalhar com vocês. Aprendi muito nestes cinco anos. Agradeço também ao incentivo a pós-graduação, apoio e compreensão.

\section{Ao SEMPRE}

Obrigada aos profissionais coordenadores deste Serviço pela receptividade na realização deste estudo. Aos funcionários pela colaboração e em especial a todas as pessoas diabéticas que concordaram em participar do estudo.

\section{A nutricionista Adriana Garcia Peloggia de Castro}

Agradeço a confiança e sua ajuda despojada quando recorri a você.

\section{Prof $^{a}$ Dr $^{a}$ Carla Regina de Souza Teixeira}

Obrigada pela atenção e sugestões

\section{Aos nutricionistas do Hospital das Clínicas - Unidade de Emergência}

Obrigada pelas dicas, orientações e compreensão nos momentos difíceis.

\section{Aos meus parentes e amigos}

Agradeço o apoio, força e as orações.

\section{Ao meu amor, James}

Suas sugestões e olhar especial contribuíram muito com este estudo. Obrigada pela compreensão, companhia e carinho. Te amo!

\section{A Deus}

Que sem a sua permissão, este trabalho não teria sido possível. Muito obrigada Senhor, por tua mão sobre toda minha vida e em especial por ter usado de todas as pessoas que me ajudaram durante o desenvolvimento deste sonho. 


\section{Sumário}

- Resumo

- Abstract

- Resumén

1. Introdução 01

1.1 Diabetes Mellitus como uma condição crônica de saúde 01

1.2 Terapia Nutricional no Diabetes Mellitus 04

1.3 Considerações sobre adoçantes e alimentos diet e light 08

2. Problema de Estudo 16

$\begin{array}{ll}\text { 3. Objetivos } & 17\end{array}$

3.1 Objetivo Geral 17

$\begin{array}{ll}3.2 \text { Objetivos Específicos } & 17\end{array}$

4. Material e Métodos 18

4.1 Tipo de estudo 18

$\begin{array}{ll}4.2 \text { Local do estudo } & 18\end{array}$

4.3 População do estudo 20

4.4 Variáveis do estudo 20

4.5 Instrumento de coleta de dados $\quad 21$

4.6 Estudo piloto 22

4.7 Período do estudo $\quad 22$

4.8 Coleta de dados $\quad 22$

4.9 Organização dos dados para análise 23

4.10 Aspectos éticos 23

5. Resultados $\quad 24$

5.1 Variáveis sócio-demográficas e relacionadas à doença 24

5.2 Variáveis relacionadas ao consumo de adoçantes e alimentos diet e light 28

6. Discussão 39

$\begin{array}{ll}\text { 7. Conclusões } & 46\end{array}$

8. Considerações Finais $\quad 48$

9. Referências 50

10. Anexos 56 


\section{Resumo}

SOUSA, G. Uso de adoçantes e alimentos dietéticos por pessoas diabéticas. 2006 64p Dissertação de mestrado - Escola de Enfermagem de Ribeirão Preto, Universidade de São Paulo, Ribeirão Preto.

O impacto do diabetes mellitus como sério problema de saúde pública está no fato de que a maioria das complicações crônicas inerentes a doença é incapacitante para a realização das atividades diárias e produtivas, compromete a qualidade de vida e é onerosa para o sistema de saúde. A terapia nutricional é parte fundamental do cuidado do diabetes e tem como principal alvo manter a glicemia mais próxima possível do valor normal, balanceando dieta, medicamentos e exercício físico. É comum o uso de adoçantes dietéticos em substituição ao açúcar por pessoas com diabetes, pois possuem alto poder adoçante conferindo ao alimento pouca ou nenhuma caloria. O presente estudo tem como objetivo investigar o uso de adoçantes e alimentos dietéticos por pessoas diabéticas cadastradas em um Serviço de Medicina Preventiva - SEMPRE do interior do Estado de São Paulo. Para tanto, os dados foram obtidos por meio de um questionário composto de variáveis sócio-demográficas, variáveis relacionadas à doença e referentes ao consumo de adoçantes e alimentos dietéticos. Os dados foram registrados em planilhas construídas no MS Excel e a análise estatística foi realizada através do programa SPSS. A coleta de dados ocorreu nos meses de novembro e dezembro de 2005. Participaram do estudo 65 pessoas diabéticas, sendo $57(87,7 \%)$ do tipo 2 e $5(7,7 \%)$ do tipo 1 . Respondem aos objetivos específicos deste estudo os seguintes resultados: houve predomínio de usuários do sexo feminino, idosos, casados, com ensino superior completo e renda familiar elevada. O tempo de diagnóstico médio foi de 13,9 anos. Quanto ao conhecimento acerca da doença, as respostas mais freqüentes foram: diabetes como excesso de açúcar no sangue e defeito do pâncreas para produzir quantidade adequada de insulina. Constatou-se consumo maior de aspartame em relação a outros edulcorantes. $\mathrm{O}$ fator que mais influenciou os usuários na escolha do adoçante foi o sabor. Verificou-se que os diabéticos deste estudo controlam a quantidade de seu adoçante no momento do uso. O refrigerante dietético é o produto dietético mais consumido pelos entrevistados, seguido pela gelatina. Alguns fatores que interferem no uso de adoçantes e alimentos dietéticos para esta população são: informações incorretas a respeito de tais produtos, preferência pelo sabor doce e a desconfiança e custo elevado dos alimentos dietéticos industrializados. Conclui-se que são necessários maiores esclarecimentos às pessoas diabéticas quanto ao uso de adoçantes e alimentos dietéticos, através de informações nutricionais mais completas nos rótulos destes produtos e por intermédio da orientação por parte dos profissionais de saúde que acompanham essas pessoas.

Palavras-chave: diabetes mellitus, adoçantes dietéticos, alimentos dietéticos 


\begin{abstract}
SOUSA, G. Use of sweeteners and diet food by diabetic people. 2006 64p Masters Degree Dissertation - Escola de Enfermagem de Ribeirão Preto, Universidade de São Paulo, Ribeirão Preto.
\end{abstract}

The diabetic mellitus impact as a serious problem to the public health is in fact that the disease major chronic complication is the incapability to realize daily and productive activity, compromise the life quality and is costly to the health-system. The nutritional therapy is a fundamental part of diabetic care and has as a main target to keep the glicemia closer as possible to the normal value, balancing diet, medicine and physical activity. It is common use diet sweeteners as a replacement for sugar by diabetic persons, since they have a high sweetening level giving the food little or no calorie. The present study has a aim to check the use of diet sweeteners and diet foods by diabetics registered in the Serviço de Medicina Preventiva (Preventative Medicine Service) - SEMPRE, in the countryside of São Paulo State. In order to achieve this, data were obtained by means of a questionnaire consisting of socio-demographic variables, variables related to the disorder and referring to the consumption of diet sweeteners and food. The data was registered in MS Excel worksheets and the statistical analysis was performed using the SPSS software. The gathering of said data took place between November and December of the year of 2005. Sixty five diabetic patients took part in the study, 57 (87,7\%) being of type 2 and 5 (7,7\%) being of type 1 . The following results respond to the specific goals of this study: there was a predominance of female users, elderly, married, with completed college education courses and high familiar income. The average time of diagnosis was 13,9 years. As far as knowledge about the disorder was concerned, the most frequent answers were diabetes as an excess of sugar in the blood; and the pancreas failing to produce the adequate amount of insulin. A higher consumption of aspartame was found, compared to other sweeteners. Users were most influenced by taste when choosing a sweetener. It was verified that the diabetics participating in this study control the amount of sweetener consumption when using it. The diet soft drink is the most consumed diet product, followed by jelly. Some factors that interfere with the use of sweeteners in this population are: incorrect information about such products, a preference to sweet tastes and the distrust and expensive cost of manufactured diet products. It is concluded that better clarification is necessary to diabetics when it comes to the use of diet sweeteners and food, by means of more throughout nutritional information on the labels of such products and through health professionals caring for these people.

Keywords: diabetes mellitus, diet sweeteners, diet food 


\section{Resumen}

SOUSA, G. Usanza de adulzantes y alimentos dietéticos por personas diabéticas. 2006 64p Disertacion de maestria - Escuela de Enfermaje de Ribeirão Preto, Universidade de São Paulo, Ribeirão Preto.

El impacto de la diabetes como serio problema de salud publica en el hecho de que la mayoria de las complicaciones cronicas inerentes de la enferemedad es incapacitante para la realizacion de las actividades diarias e productivas, compromete l calidad de vida y onrosa para el sistema de la salud. La terapia nutricional es parte fudamental del cuidado de diabetes y tiene como principal blanco mantener la glicerina mas proxima posible del valor normal, valanceado, dieta, medicamentos y exercicios fisicos. Es casi comun el uso de endulzantes dieteticos en sustitucion al azucar por personas con diabetes pues posee alto poder endulzante dejando al alimento poca o ninguna caloria. El presente estudio tiene como objetivo conocer el uso de endulzantes y alimentos dieteticos por personas diabeticas cadastradas en un Servicio de Medicina Preventiva - SEMPRE en el interior del estado de San Paulo. Para esos los datos fueran obtenidos por medio de un cuestionario hecho por variables socio-demográficas, variables de referencia a enfermedad y ac consumo de adulzantes y alimentos dietéticos. Los datos fueran constados en planillas elaboradas en MS Excel y el análisis estadística fue hecha por el programa SPSS. La recopilación de datos se pasó en los meses de noviembre a diciembre de 2005. Han participado del estudio 65 personas diabéticas, 57 (87,7\%) del tipo 2 y $5(7,7 \%)$ del tipo 1. contestan las finalidades específicas de este estudio los siguientes resultados: hubo mayoria de usuarios del sexo femenino, mayores, casados, con enseñanza superior completa y rienta familiar alta. El tiempo de diagnosis mediano fue de 13,9 años. Cuanto al conocimiento sobre la enfermedad, las respuestas nas frecuentes fueran diabetes con excesiva açúcar en la sangre y facca en el páncreas en la producción de insulina. Fue constado usanza más grande de aspartame lo que más influenció los usuarios en la ececcion del edulzante fue el sabor. Ea gaseosa dietética es el más consumido por los entrevistados, luego la gelatina. Algunos factores que causan interferencia en el uso de adulzantes y alimentos dietéticos entre las personas son: informes incorrectos respecto a tales productos y no fianza y coste subido de los alimentos diet industrializados. La conclusión es que son necesarios mayores esclarecimentos a personas diabéticas ala usanza de adulzantes y dietéticos, por informes nutricionales más eficaces en los marbetes de esos productos por medio de los profesionales de la salud que siguem tales personas.

Palabras Ilaves: diabetes mellitus, adulzantes dietéticos, alimentos dietéticos 


\section{Introdução}

\subsection{Diabetes mellitus como uma condição crônica de saúde}

Diabetes mellitus corresponde a um grupo de doenças metabólicas caracterizadas por hiperglicemia resultante de defeitos na secreção de insulina, na ação da insulina ou em ambas. A hiperglicemia crônica do diabetes está associada com dano a longo prazo, disfunção e insuficiência de vários órgãos, especialmente dos olhos, rins, nervos, coração e vasos sanguíneos (SBD, 2003a; AMERICAN DIABETES ASSOCIATION, 2004b; COSTA; ALMEIDA NETO, 2004).

A maioria dos casos de diabetes está incluída em duas grandes categorias etiopatogenéticas: diabetes tipo 1 e diabetes tipo 2 (ADA, 2004b).

O diabetes mellitus tipo 1 resulta de uma destruição auto-imune, mediada por células beta do pâncreas. Os marcadores da destruição imune das células beta incluem os auto-anticorpos contra as células das ilhotas, auto-anticorpos contra a insulina, auto-anticorpos contra a descarboxilase do ácido glutâmico e auto-anticorpos contra as tirosina-fosfatases IA-2 e IA-2 $\beta$. Esta forma de diabetes é responsável por apenas 5-10\% dos casos de diabetes e comumente ocorre na infância e na adolescência, mas pode ocorrer em qualquer idade, até mesmo na oitava e nona décadas de vida (DAVIDSON, 2001; ADA, 2004b).

Diabetes tipo 2 envolve indivíduos que têm resistência à insulina e, usualmente, apresentam deficiência relativa de insulina. Ocorre em 90-95\% dos casos e está freqüentemente associado com uma forte predisposição genética, mais do que a observada na forma auto-imune do diabetes

tipo 1. A obesidade, dentre as múltiplas causas para este tipo de diabetes, é observada na maior parte dos pacientes sendo que por si já causa algum grau de resistência à insulina (MANCINI, 2001; SBD, 2003a; ADA, 2004b). Este tipo de diabetes, freqüentemente, passa sem ser 
diagnosticado por muitos anos, porque a hiperglicemia desenvolve-se de forma gradual e, em estágios mais iniciais, não é suficientemente grave para que o paciente perceba quaisquer dos sintomas clássicos de diabetes; poliúria, polidpsia e perda de peso inexplicada (HARRIS, 1992).

O risco de desenvolver o diabetes tipo 2 aumenta com a idade, a obesidade, sedentarismo, história familiar de diabetes, diabetes gestacional prévio e em indivíduos com hipertensão arterial ou dislipidemia (COSTA; ALMEIDA NETO, 2004).

O diabetes mellitus gestacional é definido como qualquer grau de intolerância à glicose, diagnosticada pela primeira vez na gestação, podendo ou não persistir após o parto (ADA, 2004b; COSTA; ALMEIDA NETO, 2004).

Os outros tipos específicos de diabetes mellitus referem-se a defeitos genéticos das células beta, defeitos genéticos na ação da insulina, doenças do pâncreas exócrino, endocrinopatias, diabetes induzido por drogas e agentes químicos, infecções, formas incomuns de diabetes imunemediados e outras síndromes genéticas associadas com diabetes (ADA, 2004b).

Nos últimos anos, o diabetes mellitus vem se destacando entre as doenças crônicas nãotransmissíveis de reconhecimento mundial, como problema de saúde pública. Sua importância não está somente em virtude do aumento de sua prevalência e incidência, mas também pelas repercussões sociais e econômicas dele decorrentes, tais como mortes prematuras, absenteísmo e incapacidade para o trabalho (LERÁRIO, 1998; SANCHES, 2000). Esse aumento nas últimas décadas ocorre tantos nos países desenvolvidos como nos países em desenvolvimento e existe uma tendência para continuar aumentando nos próximos anos (KING et al., 1998).

Estima-se que o diabetes deverá atingir 200 milhões de pessoas em todo o mundo até o ano 2010, o que representa o dobro dos valores observados em 1994 (MC CARTY; ZIMMET, 1994).

Calcula-se que o número de adultos com diabetes na América Latina aumente em 254\% de 14,5 milhões em 1995 para 36,8 milhões em 2025. A maior parte desse aumento será observada 
em indivíduos na faixa de 45 a 64 anos de idade, com maior concentração nas mulheres do que nos homens (KING et al., 1998).

No Brasil, estima-se que existam 5 milhões de pessoas portadoras de diabetes, das quais metade desconhece o diagnóstico (LERÁRIO, 1998). O Estudo Multicêntrico sobre a prevalência de diabetes realizado em nove capitais brasileiras, numa população com idade entre 30 a 69 anos, revelou que 7,6\% da população apresenta diabetes. Ambos os sexos mostraram-se igualmente atingidos e apresentou-se predominantemente nas camadas populacionais com idade mais elevada, chegando a 17,4\% no grupo de idade de 60 a 69 anos. (MALERBI; FRANCO, 1992; FRANCO, 1998).

No Município de Ribeirão Preto - SP estima-se 12,1\% de portadores de diabetes na população urbana com idade entre 30 a 69 anos (TORQUATO et al., 2001).

Assim, esta síndrome é hoje um dos maiores problemas de saúde pública do Brasil e está associada a complicações clínicas, que incluem desde descompensações metabólicas agudas até complicações crônicas envolvendo diferentes órgãos (vasculopatia, nefropatia, neuropatia, retinopatia) que comprometem a produtividade, qualidade de vida e sobrevida das pessoas diabéticas, além de envolver altos custos no seu tratamento e das suas complicações. O diabetes mellitus contribui para o aumento considerável da morbidade e mortalidade, que podem ser reduzidos com diagnóstico e tratamento precoces (BURGOS et al., 2002).

O Diabetes Control and Complications Trial - DCCT (DCCT, 1993; ADA,1999b) mostrou que para diabetes mellitus tipo 1, o grau de hiperglicemia está diretamente relacionado com a ocorrência das complicações microvasculares como a retinopatia e a nefropatia.

Para o diabetes mellitus tipo 2, no entanto, as informações mais conclusivas vieram do United Kingdom Prospective Diabetes Study (UKPDS, 1998; ADA, 1999c), realizado em diabéticos tipo 2. Após um período de dieta de três meses, os pacientes foram sorteados 
aleatoriamente para terapia com insulina ou antidiabético oral e para um grupo convencional, tratado apenas com dieta. Esse estudo acompanhou os pacientes por um tempo médio de 10 anos e durante esse período, a diferença dos valores de HbA1c foi de 0,9\%, sendo 7\% no grupo em tratamento intensivo e 7,9\% no controle. Essa diferença foi associada com uma significativa redução de $25 \%$ para os desfechos microvasculares quando comparada com o grupo convencional.

O bom controle metabólico, representado pelo controle glicêmico e da lipidemia previne ou retarda as complicações associadas à doença (SAMPAIO, 2000).

O tratamento do diabetes mellitus envolve algumas estratégias como educação, mudanças no estilo de vida, alimentação adequada, prática de atividade física regular, suspensão do fumo, realização do controle domiciliar da glicemia e utilização correta e regular da medicação prescrita quando necessário (SÃO PAULO, 2001; SBD, 2003a).

A alimentação é um dos elementos mais importantes do plano terapêutico e em alguns casos, a única intervenção necessária. Dentre as várias vertentes do tratamento no diabetes terá maior destaque neste estudo, a terapia nutricional no diabetes.

\subsection{Terapia Nutricional no Diabetes Mellitus}

A terapia nutricional em diabetes é um aspecto fundamental do tratamento para se obter e manter o estado metabólico adequado. Tem como objetivos: alcançar e manter os parâmetros metabólicos satisfatórios; prevenir e tratar as complicações agudas e crônicas do diabetes; melhorar a saúde através da escolha de alimentos saudáveis e atividade física, e abordar as necessidades nutricionais individuais levando em consideração preferências pessoais, culturais e estilo de vida (GEDAPS, 2000; SACHS, 2002). 
A terapia nutricional passou no século 20 por constantes modificações. Em 1912, Frederick M. Allen (1914, apud VIGGIANO, 2001) desenvolveu a Terapêutica da Fome de Allen, oferecendo $1000 \mathrm{Kcal} /$ dia e $10 \mathrm{~g}$ de carboidratos por dia as pessoas diabéticas com o objetivo de manter os indivíduos vivos até que, supostamente, a insulina voltasse a tornar-se disponível. Deste modo, até o surgimento da insulina exógena, os diabéticos eram tratados com dietas muito baixas em carboidratos. Mesmo após a terapia com insulina em 1921, os estudiosos ainda recomendavam a dieta pobre em carboidratos e rica em lípides, porque poucos estudos e, ainda, não conclusivos como os de Sansum et al. (1926, apud VIGGIANO, 2001), Geyelin et al. (1935, apud VIGGIANO, 2001) e Kempner et al. (1958, apud VIGGIANO, 2001), demonstravam os benefícios da dieta com maior aporte de glícides e menor de lípides.

Tradicionalmente, os indivíduos diabéticos têm sido orientados a restringir a ingestão de alimentos que agravam a hiperglicemia, aumentam as concentrações de triglicérides séricos e promovam ganho de peso. Geralmente, esses alimentos muito calóricos como os doces e alimentos industrializados contêm quantidades excessivas de gorduras e açúcares, contribuindo para mau controle metabólico. Esta restrição também observou-se entre as décadas de 60 e 90 , em análise das recomendações nutricionais sobre o consumo de açúcares, afim de manter a saúde geral de toda população (FREIRE; CANNON, 1994).

Entretanto, no decorrer das últimas décadas, as recomendações nutricionais para indivíduos com diabetes foram sendo modificadas. De dietas extremamente restritas em carboidratos e muito ricas em gorduras e colesterol, passou-se a recomendar dietas ricas em carboidratos e fibras, suficiente em proteínas e restritas em gorduras saturadas e colesterol, como pode ser observado no Quadro 1. 
Quadro 1. Perspectiva histórica sobre as Recomendações Nutricionais no Diabetes Mellitus

\begin{tabular}{|c|c|c|c|c|c|}
\hline 1921 & 1950 & & & 1986 & 1994 \\
\hline CHO $20 \%$ & $\mathrm{CHO} 40 \%$ & $\mathrm{CHO}$ & $45 \%$ & CHO até $60 \%$ & $\mathrm{CHO}$ a \\
\hline LIP $\quad 70 \%$ & LIP $\quad 40 \%$ & LIP & $35 \%$ & LIP $<30 \%$ & LIP a, b \\
\hline PTN $10 \%$ & PTN 20\% & PTN & $20 \%$ & PTN 12-20\% & PTN 10-20\% \\
\hline
\end{tabular}

a - baseado na avaliação nutricional e nos objetivos do tratamento

$\mathrm{b}$ - menor que $10 \%$ de gordura saturada

Fonte: ADA, 1997

Historicamente, recomendações nutricionais para o diabetes e suas complicações foram baseadas em conhecimento científico, experiência clínica e consenso técnico; entretanto sempre foi difícil estabelecer o nível de evidência usado para construir as recomendações. Hoje tem-se como evidência de nível A as seguintes considerações: na alimentação da pessoa diabética devem ser incluídos alimentos como cereais integrais, frutas, hortaliças e leite desnatado. Estudos demonstraram que a ingestão de amidos ou sacarose, em quantidades semelhantes, por pessoas diabéticas não produziram diferença na resposta glicêmica. Por conseguinte, a quantidade total de carboidratos nas refeições é mais importante do que a origem ou o tipo. Uma vez que a sacarose não aumenta a glicemia mais do que quantidades isocalóricas de amido, a sacarose e os alimentos que contém sacarose não necessitam ser restringidos por pessoas com diabetes; contudo, eles devem substituir outras fontes de carboidratos ou, se forem adicionados, devem ser cobertos com insulina ou antidiabéticos orais. Entretanto, isso não deve ser compreendido como uma recomendação para aumentar a quantidade de doces consumidos. Isto somente ilustra que uma variedade de alimentos pode ser incluída conforme se enquadrem em planos de refeições bem balanceados (ADA, 2004c).

Ainda segundo a ADA (2004a) é consenso para especialistas que: carboidratos e gorduras 
monoinsaturadas juntos devem prover $60-70 \%$ da ingestão energética diária total e 15-20\% de proteínas. Contudo, o perfil metabólico e a necessidade de perder peso devem ser considerados quando da determinação do conteúdo de gordura monoinsaturada da dieta e sacarose e alimentos contendo sacarose devem ser ingeridos no contexto de uma dieta saudável.

Para realização de um plano alimentar que atenda as recomendações atuais, bem como da educação nutricional como uma das estratégias do tratamento no diabetes, o profissional nutricionista dispõe de métodos como a pirâmide alimentar e a contagem de carboidratos. A pirâmide exprime graficamente a qualidade e a quantidade dos diferentes grupos alimentares que devem ser preferencialmente ingeridos. Por traduzir-se em uma alimentação saudável e equilibrada, é um guia recomendado para composição das refeições, destinado a toda a população (VIGGIANO, 2001; SBD, 2003b; COSTA; ALMEIDA NETO, 2004). A contagem de carboidratos como estratégia de plano alimentar focaliza-se inicialmente na quantidade total de carboidratos e enfatiza a relação entre alimentos, atividade física, glicemias e medicação. Este sistema permite maior flexibilidade nas escolhas dos alimentos, uma vez que os carboidratos simples não são proibidos e podem constituir até $25 \%$ da ingestão total de carboidratos (GOVEIA; BRUNO, 2003; SBD, 2003b; COSTA; ALMEIDA NETO, 2004). Aliado a estes métodos está o conhecimento de que os carboidratos apresentam respostas diferentes na glicemia, dependendo do tipo, traduzindo-se no índice glicêmico dos alimentos, que defini-se como a relação entre o incremento da glicose sanguínea a partir de determinado alimento e o incremento da mesma quantidade de carboidrato na forma de glicose, expresso em porcentagem. Apesar das dietas de índice glicêmico baixo reduzirem a glicemia pós-prandial, a capacidade dos indivíduos de manter essas dietas a longo prazo não tem sido estabelecida (CARUSO; MENEZES, 2000; ADA, 2004a; COSTA; ALMEIDA NETO, 2004). 
Independente do método a ser escolhido na orientação da alimentação para a pessoa diabética, a individualização do plano alimentar deve ser priorizada, respeitando necessidades nutricionais, hábitos alimentares, estado fisiológico, atividade física, medicação e situação sócioeconômica (SBD, 2003a).

A individualização da terapia nutricional tem sido o ponto fundamental dentro das recomendações de todos os estudos voltados para o diabetes. Os resultados apresentados pelo Diabetes Complications Control Trial (ADA, 1999b) indicaram que as pessoas que aderiram mais que $90 \%$ do tempo ao plano alimentar individualizado, tinham em média, nível de hemoglobina glicada 0,9\% menor do que aqueles que apresentaram uma adesão à dieta de $45 \%$ do tempo.

Para Viggiano (2001), a terapia nutricional deve também estar focada na prevenção de complicações tardias e, particularmente em relação ao diabético obeso, onde a doença cardiovascular é a complicação mais comum no diabetes do tipo 2, sendo as anormalidades das lipoproteínas a principal causa da aterosclerose. Portanto, a dieta é primordial para o controle glicêmico e também para normalização dos níveis de lipoproteínas.

Segundo Sachs (2002), apesar da adesão aos princípios do plano alimentar ser um dos aspectos de maior desafio do tratamento, a terapia nutricional é um componente essencial para seu sucesso, onde o trabalho em equipe por intermédio de processo educativo se faz indispensável para que o tratamento seja eficaz e adequado.

\subsection{Considerações sobre adoçantes e alimentos diet e light}

Os adoçantes e alimentos dietéticos passaram por várias modificações em termos de legislação desde o surgimento em 1965 pela primeira vez, das expressões produtos ou alimentos dietéticos até os dias atuais. Associado a esta evolução na legislação, está a comercialização de tais produtos no Brasil que se caracteriza por duas fases. A primeira vai de 1969 até 1987, quando 
o adoçante a base de ciclamato era o principal produto comercializado, período em que eram registrados na Divisão Nacional de Vigilância Sanitária de Medicamentos (DIMED) e, portanto, as farmácias detinham praticamente $100 \%$ das vendas. A segunda fase corresponde ao período de 1988 a 1993, com o surgimento dos adoçantes a base de aspartame. Nesta época os produtos que tinham em sua composição os edulcorantes têm grande ascensão e liberação para venda em supermercados, pois passaram a ser registrados na Divisão Nacional de Vigilância Sanitária de Alimentos (DINAL) (OLIVEIRA; ASSUMPÇÃO, 2000).

A mais recente legislação brasileira em vigor é a Portaria nº 38 de 13 de janeiro de 1998, que define adoçante dietético como "um produto formulado para dietas com restrição de sacarose, frutose e glicose (dextrose), para atender às necessidades de pessoas sujeitas à restrição de ingestão desses açúcares” (BRASIL, 1998a).

É comum para diabéticos que restringem o consumo de açúcares do seu plano alimentar, o uso de adoçantes dietéticos e alimentos dietéticos industrializados que levam a adição de substâncias que adoçam, conferindo ao alimento, pouca ou nenhuma caloria (CASTRO; FRANCO, 2002). Tais substâncias são denominadas edulcorantes, que possuem um poder adoçante muito superior à sacarose - Quadro 2. Podem ser artificiais ou naturais. Os adoçantes dietéticos podem ser classificados em dois grupos principais: os não nutritivos ou não-calóricos como a sacarina, ciclamato, acessulfame-k, aspartame, sucralose e esteviosídio, por não fornecerem calorias ou no caso do aspartame que apesar de fornecer 4Kcal/g, estas tornam-se desprezíveis devido ao seu alto poder de doçura, justificando seu uso em pequenas quantidades. Os nutritivos são a frutose, mel, sacarose, maltose, glicose, sorbitol, manitol, xilitol, pois contêm calorias (NAKASATO; ISOSAKI; VIEIRA, 1999). 
Quadro 2 - Poder de doçura dos edulcorantes em relação à sacarose

\begin{tabular}{|ll|}
\hline Edulcorantes & Doçura \\
\hline Sucralose & 600 vezes maior \\
Sacarina & 300 vezes maior \\
Esteviosídio & 300 vezes maior \\
Aspartame & 200 vezes maior \\
Acessulfame-K & 200 vezes maior \\
Ciclamato & 40 vezes maior \\
\hline
\end{tabular}

FREITAS, 2005, p. 64

O uso dos edulcorantes não nutritivos é avaliado por corporações governamentais de todo o mundo como, a Administração de Drogas e Alimentos - FDA nos Estados Unidos, Scientific Commitee on Food - SCF na Europa, e o Joint Expert Committee of Food Additions - JECFA (AMERICAN DIETETIC ASSOCIATION, 2004).

Segundo a ADA (2004a), edulcorantes não nutritivos são seguros quando consumidos dentro dos níveis de ingestão diárias aceitáveis estabelecidos pela FDA. Em relação a edulcorantes calóricos, não recomenda a frutose para ser usada como um adoçante pelo fato de que possa aumentar os lipídios plasmáticos se consumida em excesso. No entanto, não é necessário que diabéticos evitem a frutose encontrada naturalmente nas frutas e hortaliças.

A FDA aprovou quatro adoçantes não nutritivos para uso nos EUA - sacarina, aspartame, acesulfame-k, e sucralose (ADA, 2004a).

Os alegados efeitos danosos dos adoçantes artificiais não tem fundamentação científica. A OMS recomenda seu uso dentro de limites seguros, em termos de quantidade e, do ponto de vista qualitativo, recomenda alternar os diferentes tipos periodicamente afim de evitar possíveis efeitos cumulativos dos edulcorantes ao longo de anos de uso (SBD, 2003a). 
A ingestão diária aceitável - IDA é expressa em miligramas (mg) por quilo de peso corporal e significa a quantidade de edulcorante máxima permitida diariamente por toda a vida sem causar danos à saúde - Quadro 3. É estimada pelo Joint FAO/WHO Expert Committee on Food Additives - JECFA, um comitê de peritos em aditivos alimentares ligados a FAO/OMS que avalia e reavalia substâncias. Este comitê também aprova o limite tecnológico dos edulcorantes, ou seja, o teor máximo permitido para ser adicionado a alimentos industrializados (FREITAS, 2005).

Quadro 3 - Valores da IDA dos edulcorantes não nutritivos

\begin{tabular}{|ll|}
\hline Edulcorantes & IDA \\
\hline Aspartame & $40 \mathrm{mg} / \mathrm{Kg}$ de peso/dia \\
Acessulfame-K & $15 \mathrm{mg} / \mathrm{Kg}$ de peso/dia \\
Sucralose & $15 \mathrm{mg} / \mathrm{Kg}$ de peso/dia \\
Ciclamato & $11 \mathrm{mg} / \mathrm{Kg}$ de peso/dia \\
Esteviosídio & $5,5 \mathrm{mg} / \mathrm{Kg}$ de peso/dia \\
Sacarina & $5 \mathrm{mg} / \mathrm{Kg}$ de peso/dia \\
\hline
\end{tabular}

FREITAS, 2005, p. 63

A maioria dos fabricantes de adoçantes não disponibiliza na lista de ingredientes da embalagem, a quantidade em miligramas dos edulcorantes que os contém, por constituir-se de declaração opcional, não sendo possível desta forma, calcular o limite de gotas ou pó pela IDA de cada edulcorante. Para exemplificar este cálculo temos que, a quantidade máxima de aspartame que um adulto de $60 \mathrm{Kg}$ pode ingerir diariamente, com segurança, é de 2.400mg, o que equivale, aproximadamente, ao consumo de 48 envelopes de $1 \mathrm{~g}$ de um adoçante dietético com 5\% de aspartame. Ao realizar consulta a alguns fabricantes através do serviço de atendimento ao consumidor, com a finalidade de conhecer a quantidade em miligramas dos edulcorantes contidos 
na embalagem, obteve-se que esta informação não pode ser revelada por tratar-se de segredo de fabricação. Nakasato (1999) também verificou em seu estudo, que as informações nutricionais dos rótulos de adoçantes, quando existem, são insuficientes, exigindo que as pessoas procurem o serviço de atendimento ao consumidor para maiores esclarecimentos. Por meio desta mesma consulta, foram obtidas orientações de uma a catorze gotas por quilo de peso ao dia, dependendo do tipo de edulcorante contido no adoçante e de 1,17 envelopes de 1 grama por quilo de peso ao dia para um adoçante em pó a base de aspartame. Embora o limite diário de gotas ou pó dos adoçantes seja normalmente difícil de ser superado, no caso dos refrigerantes isso não ocorre. Entre doze tipos diferentes de refrigerantes pesquisados, oito deles contém grande quantidade de ciclamato, podendo assim limitar a ingestão. Por exemplo: considerando um indivíduo adulto de 75Kg, sua IDA para o ciclamato seria de 825mg (11mg x 75Kg). Para não ultrapassar esta ingestão máxima, o consumo destes refrigerantes seria de 4 a 7,5 copos de 200ml/dia.

Segundo a Portaria $n^{\circ} 29$ de 13 de janeiro de 1998, alimentos para fins especiais são os alimentos especialmente formulados ou processados, nos quais se introduzem modificações no conteúdo de nutrientes, adequados à utilização em dietas, diferenciadas ou opcionais, atendendo às necessidades de pessoas em condições metabólicas e fisiológicas específicas. Classificam-se em:

1. Alimentos para dietas com restrição de nutrientes:

a) alimentos para dietas com restrição de carboidratos

b) alimentos para dietas com restrição de gorduras

c) alimentos para dietas com restrição de proteínas

d) alimentos para dietas com restrição de sódio

e) outros alimentos destinados a fins específicos 
2. Alimentos para ingestão controlada de nutrientes
a) alimentos para controle de peso
b) alimentos para praticantes de atividade física
c) alimentos para dietas para nutrição enteral
d) alimentos para dietas de ingestão controlada de açúcares
e) outros alimentos destinados a fins específicos

3. Alimentos para grupos populacionais específicos
a) alimentos de transição para lactentes e crianças de primeira infância
b) alimentos para gestantes e nutrizes
c) alimentos à base de cereais para alimentação infantil
d) fórmulas infantis
e) outros alimentos destinados aos demais grupos populacionais específicos.

O termo diet pode ser utilizado para alguns alimentos para fins especiais como aqueles formulados para dietas com restrição de nutrientes, alimentos para controle de peso e alimentos formulados para dietas de ingestão controlada de açúcares. Assim, os alimentos dietéticos são modificados não necessariamente no conteúdo de açúcar ou carboidratos, podendo também ser isentos de gorduras, proteínas ou de sódio. Para um alimento ser considerado diet para açúcares deve ser isento ou conter no máximo 0,5\% de açúcares de adição em sua composição. No entanto, segundo a legislação produtos que contenham açúcares naturais dos ingredientes também podem receber a denominação diet (BRASIL, 1998b).

Com relação aos alimentos denominados light é necessário que haja pelo menos 25\% de redução de um determinado nutriente ou caloria, quando comparado ao produto convencional (BRASIL, 1998c). 
No Brasil, os produtos dietéticos estão no mercado há mais de 30 anos, porém o incremento da produção deu-se no final da década de 80 (MONEGO et al., 1994). Apesar destes produtos serem dispensáveis para o bom controle metabólico da doença, eles têm sido utilizados como aliados por diabéticos e obesos pelo fato de proporcionarem o prazer do sabor doce e a redução no total calórico da dieta como justificativa da expansão do mercado de dietéticos em todo o mundo (BERTORELLI; CZARNOWSKI-HILL, 1990; CASTRO, 1999).

Segundo dados da Associação Brasileira da Indústria de Alimentos Dietéticos - ABIAD, o mercado nacional de diet e light tem crescido $25 \%$ ao ano. A média de lançamentos passou de 40 para 180 produtos light e diet por ano na última década, quando foram lançadas 750 versões de alimentos com essas características, das quais 75\% classificadas como light. Na Argentina, por exemplo, as vendas de produtos light e diet são 60\% maiores do que no Brasil. Já nos Estados Unidos, esses alimentos representam 35\% de tudo o que os norte-americanos consomem diariamente. Estima-se que existam no país 120 indústrias de alimentos diet e light e a maior concentração de consumidores encontra-se no sudeste e no sul do país, num total de 25 milhões de consumidores (RODRIGUES, 2001). Porém, enquanto aumenta a variedade destes produtos no mercado, segundo Cavalcanti (1997) alguns consumidores ainda não diferenciam o significado dos termos diet e light modificados. Esse autor também comenta que segundo pesquisa realizada em 16 supermercados de Curitiba, cerca de 55\% dos consumidores entrevistados consomem produtos dietéticos sem orientação profissional e 57\% não lêem os rótulos dos alimentos que adquirem e consomem. 
O Instituto Brasileiro de Educação para o Consumo de Alimentos e Congêneres - IBCA em parceria com a ABIAD revelou que ainda há dúvidas em relação aos produtos diet e light. Entre os 720 consumidores ouvidos pela pesquisa, 8\% disseram não haver diferença entre os dois, 24\% afirmaram que existe uma distinção, embora sem saber responder qual. Entre os que deram uma definição, apenas 15,7\% acertaram o que são de fato produtos diet e light (PROBLEMAS..., 2005).

Adoçantes dietéticos podem ser úteis no tratamento de pacientes com diabetes. Eles podem facilitar a manutenção da dieta, já que desta forma o paciente pode tanto suprir seu desejo pelo sabor doce como também assistir o controle da ingestão calórica (NABORS; GELARDI, 1991; MONEGO et al.,1994; RAMOS; STOREL JUNIOR, 2001).

Blundell e Green (1996, apud ROSADO; MONTEIRO, 2001), referem que a substituição do açúcar pelo adoçante não energético não resulta em abstenção e sim, compensação energética principalmente em alimentos ricos em lipídios.

Segundo Mourão (2004) em estudo comparando o efeito de uma dieta com sacarose e uma com sucralose sobre o apetite e gasto energético em homens, verificou-se maior saciedade, maior gasto energético de repouso e menor fome após o consumo da dieta com sucralose quando comparada a dieta com sacarose.

Os adoçantes não nutritivos e os alimentos dietéticos, além de contribuírem para uma variação do cardápio, têm um benefício psicológico e social importante para estes pacientes, principalmente para aqueles que fazem dietas para redução de peso (CRAPO, 1988).

Dentro deste enfoque, considera-se importante conhecer o uso de adoçantes e alimentos dietéticos por pessoas diabéticas. 


\section{Problema de estudo}

A minha experiência como nutricionista desenvolvendo atividades com grupos de educação para pessoas diabéticas, obesas e hipertensas em um Serviço de Medicina Preventiva de Ribeirão Preto - SP, possibilitou-me identificar que a maioria das pessoas apresentava pouco conhecimento em relação aos adoçantes dietéticos e alimentos com restrição de nutrientes, ou seja, os produtos comercialmente denominados diet e light, representando assim, dificuldades para a compreensão do plano alimentar adequado.

A partir de março de 2003, comecei a participar do Programa de Atendimento Sistematizado a pessoa diabética do Centro Educativo de Enfermagem para Adultos e Idosos da Escola de Enfermagem de Ribeirão Preto da Universidade de São Paulo. Uma das atividades desenvolvidas por mim neste Centro, foi a orientação nutricional às pessoas diabéticas ali cadastradas. Neste grupo de pessoas diabéticas, também observei as mesmas dificuldades e necessidades acerca dos adoçantes e alimentos dietéticos.

Diante disso, cresceu o meu interesse em investigar como é o uso e qual é o conhecimento que as pessoas diabéticas têm em relação aos adoçantes e alimentos dietéticos utilizados no domicílio.

Espera-se que este trabalho contribua com informações que possam auxiliar na orientação e acompanhamento de pessoas com diabetes mellitus por profissionais da área. 


\section{Objetivos}

\subsection{Objetivo Geral:}

Investigar o uso de adoçantes e alimentos dietéticos por pessoas diabéticas do Serviço de Medicina Preventiva - SEMPRE de Ribeirão Preto - São Paulo.

\subsection{Objetivos Específicos:}

$\checkmark$ Caracterizar os usuários diabéticos segundo variáveis sócio-demográficas e relacionadas à doença.

$\checkmark$ Verificar o consumo de adoçantes por pessoas diabéticas segundo tipo, critérios de seleção e de dosagem.

$\checkmark$ Identificar, na população de diabéticos estudada, o consumo de alimentos dietéticos.

$\checkmark$ Descrever os fatores que interferem no uso de adoçantes e alimentos dietéticos. 


\section{Material e Métodos}

\subsection{Tipo de estudo}

Trata-se de um estudo observacional transversal, isto é, todas as medições são feitas em um único momento, sem período de acompanhamento. Este tipo de estudo é útil para descrever variáveis e seus padrões de distribuição, além de possuir vantagens como a rapidez e o baixo custo (HULLEY et al., 2003).

\subsection{Local do estudo}

O estudo foi realizado em uma instituição privada da cidade de Ribeirão Preto - SP. Tratase de uma cooperativa de trabalho médico que oferece assistência médica aos seus usuários em consultórios. Como também, disponibiliza serviços de urgências e emergências, serviço de home care, incluindo os atendimentos de enfermagem, nutrição, psicologia, fisioterapia, fonoaudiologia e terapia ocupacional, serviço de medicina preventiva, farmácia e convênio com hospitais para internações.

O local de estudo escolhido foi o Serviço de Medicina Preventiva (SEMPRE), inaugurado em junho de 2001. Esse serviço tem como objetivo oferecer apoio às pessoas com doenças crônicas, por meio de equipe multiprofissional de saúde e processo educativo.

Segundo Krarauer (2004), é preciso oferecer as pessoas um programa que as informe e as motive a serem protagonistas de seus tratamentos. A mensagem deve ser de linguagem clara e precisa, com informações corretas e objetivas.

O programa educativo em diabetes deve ter como objetivos, aumentar os conhecimentos sobre diabetes, desenvolver habilidades para o autocuidado, estimular a mudança de comportamento, oferecer suporte para o manejo dos problemas diários decorrentes da doença e prevenir as complicações agudas e crônicas da doença (BRASIL, 2001). 
No SEMPRE os usuários encaminhados pelos médicos, inicialmente são avaliados pela enfermeira pela triagem e posteriormente direcionados aos diferentes grupos de acordo com motivo do encaminhamento médico e avaliação da enfermeira. Os grupos são realizados nos períodos da manhã, tarde e noite. São formados por pessoas com doenças crônicas, tais como, diabetes mellitus, hipertensão arterial e obesidade tendo como fio condutor à reeducação alimentar. Também estão em seguimento as pessoas que irão submeter-se à cirurgia bariátrica e às que já realizaram esta cirurgia. Além destes, tem-se ainda os grupos de promoção à saúde, gestantes e terceira idade.

Os encontros em grupo acontecem semanalmente com duração de uma hora. A equipe multiprofissional deste serviço é formada por profissionais nutricionistas, psicólogas, enfermeiras, fisioterapeutas e terapeuta ocupacional. Cada um destes profissionais revezam suas atividades nos grupos, abordando temas pré-determinados que compõem o programa de cada profissional, através de orientações e palestras educativas. De maneira geral, os assuntos discutidos nos grupos de diabéticos por parte da nutricionista, são a respeito do plano alimentar saudável e equilibrado para a pessoa diabética. Sendo que uma das orientações diz respeito aos adoçantes e alimentos denominados diet e light, características próprias de cada um e orientações de uso. Os usuários também recebem da enfermeira, orientações acerca do conceito e classificação do diabetes, diagnóstico, fatores que precipitam o aparecimento da doença, bem como, das complicações a longo prazo decorrentes do mau controle metabólico. O SEMPRE também conta com atividades extras elaboradas pela terapeuta ocupacional e o trabalho do educador físico na academia.

Para o presente estudo elegeu-se o grupo de pessoas diabéticas. No período do estudo, estavam conformados oito grupos em atendimento, totalizando 92 usuários cadastrados, distribuídos nos períodos da manhã, tarde e noite. 


\subsection{População}

A população do estudo foi constituída por 65 pessoas do programa de atendimento multiprofissional em diabetes, pois, 4 usuários não aceitaram participar do estudo e 23 não estavam presentes nos grupos no dia da aplicação do instrumento.

\subsection{Variáveis do estudo}

\section{Variáveis sócio-demográficas}

- Sexo: foram considerados indivíduos de ambos os sexos, feminino e masculino.

- Idade: A faixa etária foi estratificada a partir da idade informada pelo usuário no momento da entrevista, segundo dia, mês e ano de nascimento. Os usuários foram distribuídos em duas classes, a saber: menos de 60 anos ou adultos e mais de 60 anos ou idosos.

- Estado civil: foi considerado solteiro, casado, divorciado/separado e viúvo.

- Escolaridade: A escolaridade foi classificada segundo informação fornecida pelo usuário, de acordo com a última série concluída. A partir destes dados, a variável foi estratificada em: alfabetizados, mas que não freqüentaram a escola, portanto com nenhuma escolaridade; ensino fundamental completo ou incompleto; ensino médio completo ou incompleto; ensino superior completo ou incompleto.

- Renda familiar: foi considerada a renda obtida por todos os membros do domicílio, informada pelo usuário e calculada em salários mínimos. 


\section{Variáveis relacionadas à doença}

- Tipo de diabetes: foi considerado o tipo de diabetes informado pelo usuário no momento do preenchimento do questionário.

- Tempo da doença: foi calculado a partir da idade referida quando se diagnosticou o diabetes e a idade atual do usuário.

- Conhecimento da doença: o conhecimento refere-se ao conceito de diabetes que foi considerado correto quando o usuário referiu: 1. excesso de açúcar no sangue, 2. defeito do pâncreas para produzir insulina em quantidades adequadas e 3. dificuldade do corpo para utilizar a insulina; ou conceito correto, porém, incompleto se a pessoa referiu uma ou duas das respostas acima. Foi considerado conceito incorreto quando o usuário não referiu nenhuma das respostas acima.

\section{Variáveis relacionadas ao consumo de adoçantes e alimentos dietéticos}

- Tipo de adoçante: os adoçantes foram classificados em naturais ou artificiais e calóricos e não calóricos.

- Critérios de escolha do adoçante: foram considerados todos os critérios referidos.

- Critérios de dosagem do adoçante: todos os critérios de dosagem foram considerados.

- Consumo de outros alimentos dietéticos: foram considerados o consumo de todos alimentos referidos.

\subsection{Instrumento de coleta de dados}

O instrumento utilizado foi um questionário adaptado, tomando por base o estudo de Castro (1999) e considerando as variáveis do estudo e a experiência pessoal do pesquisador. As 
alterações realizadas no instrumento de Castro (1999) para adaptação a este estudo foram: modificações na estrutura de algumas perguntas e alternativas de respostas, exclusão de 11 questões e inclusão de outras 4, investigando conhecimento sobre a composição do adoçante utilizado, troca e freqüência diária do mesmo, conceitos de diet e light e maneiras de identificalos no momento da compra.

O questionário contém três partes: a) dados sócio-demográficos, b) dados relacionados a doença e c) dados referentes ao consumo de adoçantes e alimentos dietéticos, totalizando 53 questões fechadas (Anexo). A apreciação do instrumento por duas nutricionistas também contribuiu para sua adaptação, quanto ao conteúdo e forma de elaboração das questões.

\subsection{Estudo piloto}

O estudo piloto foi realizado no Centro Educativo de Enfermagem para Adultos e Idosos da EERP-USP afim de adequar o instrumento aos propósitos da pesquisa. A aplicação dos questionários ocorreu no mês de março de 2005, com cinco pessoas escolhidas aleatoriamente do Programa de Atendimento ao paciente diabético, em sala privativa com a pesquisadora e com duração média de trinta minutos. O estudo piloto possibilitou ajustar o instrumento quanto a seqüência e número das questões, como também a inclusão de outras relevantes.

\subsection{Período da coleta de dados}

A coleta de dados foi realizada nos meses de novembro e dezembro de 2005.

\subsection{Coleta de dados}

Após a obtenção de autorização do médico responsável pelo SEMPRE, para a realização do estudo, iniciou-se a coleta de dados nos 8 grupos do programa de atendimento multiprofissional em diabetes distribuídos nos períodos da manhã, tarde e noite. Os usuários não foram avisados previamente da pesquisa e sim no momento em que se realizava cada grupo. No 
início dos grupos após minha identificação, foi feito o convite a todos os usuários assim como os esclarecimentos quanto a natureza e objetivos da pesquisa. Posteriormente, foram distribuídos os questionários aos usuários que aceitaram participar do estudo, na própria sala onde se reúne cada grupo e o termo de consentimento livre e esclarecido foi assinado (Anexo). O instrumento foi auto-aplicável e as orientações acerca do preenchimento do questionário foram realizadas pela pesquisadora que se colocava a disposição para os esclarecimentos que se fizessem necessários.

O tempo para o preenchimento do questionário foi de aproximadamente uma hora. Após a entrega, pelos usuários, os questionários foram conferidos para verificar questões que não foram preenchidas e seus motivos como por esquecimento, por não saber a resposta e recusa em responder a questão. Aos que referiram esquecimento, foi pedido que respondessem a questão, aos que não sabiam a resposta foi pedido que assinalassem a alternativa "não sabe” e aos que se recusaram foi respeitada a decisão.

\subsection{Organização dos dados para análise}

Inicialmente o instrumento foi codificado e padronizado. Após isto, elaborou-se um dicionário (codebook) com a codificação estabelecida para cada uma das variáveis do estudo. Posteriormente, construiu-se um banco de dados utilizando-se o programa MS Excel, sendo em seguida validado mediante procedimento de dupla entrada (digitação). A análise estatística foi realizada com o programa SPSS (Statistical Package for the Social Science, versão 11.5).

\subsection{Aspectos éticos}

O projeto de pesquisa foi aprovado pelo Comitê de Ética em Pesquisa da EERP-USP em 17 de março de 2004 atendendo à Resolução nº 196/96 do Conselho Nacional de Saúde (Anexo). 


\section{Resultados}

Alguns resultados não totalizaram percentuais 100\%, devido ao respeito às questões não respondidas. Assim como alguns somaram mais de 65 respostas, pois várias questões aceitavam mais de uma alternativa como resposta.

A seguir, apresentam-se os resultados de acordo com os objetivos propostos no presente estudo.

\subsection{Variáveis sócio-demográficas e relacionadas à doença}

Dos 65 (100,0\%) usuários diabéticos dos tipos 1 e 2 investigados, 43 (66,2\%) são do sexo feminino e 22 (33,8\%) masculino.

Quanto à idade, esta variou de 28 a 85 anos, com média de 64,4 anos e mediana de 65 anos, com predomínio de usuários com idade superior a 60 anos.

Quanto ao estado civil encontramos maior freqüência de usuários casados.

No que se refere à escolaridade todos são alfabetizados, mas 2 (3,1\%) não cursaram educação formal. Destaca-se que 55,6\% dos homens cursaram o ensino superior completo e que a maioria das mulheres $(88,2 \%)$ cursou apenas até o ensino fundamental incompleto.

Em relação à renda familiar esta variou de menos de um salário mínimo a pouco mais de trinta e três e a mediana foi de dois mil duzentos e dez reais (Tabela 1). 
Tabela 1 - Distribuição numérica e percentual dos usuários diabéticos cadastrados no SEMPRE, segundo as variáveis sócio-demográficas de Ribeirão Preto - São Paulo, 2005.

\begin{tabular}{|c|c|c|c|c|c|c|}
\hline \multirow[t]{2}{*}{ Sexo } & \multicolumn{2}{|c|}{ Masculino } & \multicolumn{2}{|c|}{ Feminino } & \multicolumn{2}{|c|}{ Total } \\
\hline & $\mathbf{N}$ & $\%$ & $\mathbf{N}$ & $\%$ & $\mathbf{N}$ & $\%$ \\
\hline \multicolumn{7}{|l|}{ Faixa etária (anos) } \\
\hline$<60$ & 6 & 42,9 & 8 & 57,1 & 14 & 21,5 \\
\hline$>60$ & 16 & 31,4 & 35 & 68,6 & 51 & 78,5 \\
\hline Total & 22 & 33,8 & 43 & 66,2 & 65 & 100,0 \\
\hline \multicolumn{7}{|l|}{ Estado civil } \\
\hline Solteiro & 2 & 33,3 & 4 & 66,7 & 6 & 9,2 \\
\hline Casado & 17 & 47,2 & 19 & 52,8 & 36 & 55,4 \\
\hline Divorciado/separado & 0 & 0 & 4 & 100,0 & 4 & 6,2 \\
\hline Viúvo & 3 & 15,8 & 16 & 84,2 & 19 & 29,2 \\
\hline Total & 22 & 33,8 & 43 & 66,2 & 65 & 100,0 \\
\hline
\end{tabular}

\section{Escolaridade}

\begin{tabular}{lcccccc} 
Alfabetizado (sem escola) & 0 & 0 & 2 & 100,0 & 2 & 3,1 \\
Ensino fundamental completo & 4 & 40,0 & 6 & 60,0 & 10 & 15,4 \\
Ensino fundamental incompleto & 2 & 11,8 & 15 & 88,2 & 17 & 26,2 \\
Ensino médio completo & 4 & 26,7 & 11 & 73,3 & 15 & 23,1 \\
Ensino médio incompleto & 0 & 0 & 1 & 100,0 & 1 & 1,5 \\
Ensino superior completo & 10 & 55,6 & 8 & 44,4 & 18 & 27,7 \\
Ensino superior incompleto & 2 & 100,0 & 0 & 0 & 2 & 3,1 \\
\hline Total & 22 & 33,8 & 43 & 66,2 & 65 & 100,0 \\
& & & & & & \\
\hline Renda familiar & & & & & & \\
$<3$ ] s.m. & 1 & 25 & 3 & 75 & 4 & 7,0 \\
(3 - 5] s.m. & 5 & 31,3 & 11 & 68,8 & 16 & 28,1 \\
$>$ 5 s.m. & 14 & 37,8 & 23 & 62,2 & 37 & 64,9 \\
\hline Total & 20 & 35,1 & 37 & 64,9 & 57 & 100,0
\end{tabular}

Oito usuários não informaram a renda

* salário mínimo vigente de R \$300,00

Ao verificar o tipo de diabetes mellitus referido pelos usuários, obteve-se que 57 (87,7\%) tem diabetes tipo 2, 5 (7,7\%) tem diabetes tipo 1 e 3 (4,6\%) não souberam referir o tipo de diabetes. 
Quanto ao tempo da doença referido pelos usuários, o menor tempo encontrado foi de menos de 1 ano e o maior de 63 anos, com média de 13,9 anos e mediana de 9 anos. Vinte usuários (30,8\%) tem o diagnóstico de até 5 anos, 23 (35,4\%) de 6 a 15 anos e 22 (33,8\%) há mais de 16 anos.

No que se refere ao conhecimento que os usuários têm em relação à doença, verifica-se que 64 deles (98,5\%) conhecem o conceito de diabetes, e 1 (1,5\%) não. Dos 64, 39 deles (61,9\%) responderam que o diabetes é excesso de açúcar no sangue, 38 (60,3\%) assinalaram o diabetes como um defeito do pâncreas para produzir quantidade adequada de insulina e 10 (15,9\%) como sendo uma dificuldade do corpo para utilizar a insulina, lembrando que os usuários podiam assinalar mais de uma alternativa. A Tabela 2 distribui os 65 usuários do estudo de acordo com o número de alternativas assinaladas em relação ao conhecimento da doença, isto é, quantos usuários consideraram somente uma alternativa correta, quantos consideraram duas alternativas corretas e quantos julgaram que as três alternativas estavam corretas e, portanto sendo considerado conceito completo do que é o diabetes.

Tabela 2 - Conhecimento da doença pelos usuários diabéticos cadastrados no SEMPRE, segundo o número de alternativas corretas assinaladas, Ribeirão Preto - São Paulo, 2005.

\begin{tabular}{cccccc}
\hline $\begin{array}{c}\text { Conhecimento } \\
\text { da doença* }\end{array}$ & \multicolumn{3}{c}{ Número de alternativas assinaladas } & Total &
\end{tabular}

\begin{tabular}{ccccccc}
\hline Não & N & $1(100,0 \%)$ & $0(0 \%)$ & $0(0 \%)$ & $0(0 \%)$ & $1(100,0 \%)$ \\
Sim & N & $1(1,6 \%)$ & $46(71,9 \%)$ & $10(15,6 \%)$ & $7(10,9 \%)$ & $64(100,0 \%)$ \\
\hline Total & $\mathbf{N}$ & $2(3,1 \%)$ & $46(70,8 \%)$ & $10(15,4 \%)$ & $7(10,8 \%)$ & $65(100,0 \%)$
\end{tabular}

* múltiplas respostas

Ainda em relação ao conhecimento da doença, segundo a faixa etária e tempo de diagnóstico, verifica-se na Tabela 3 que as respostas mais assinaladas pelos usuários adultos (< 
60 anos) foram a dificuldade do corpo para utilizar a insulina (88,9\%) e excesso de açúcar no sangue (88,9\%), para aqueles com seis anos ou mais de doença. Para os usuários idosos (> 60 anos) foram a dificuldade do corpo para utilizar a insulina (88,6\%), para aqueles com seis anos ou mais de doença e defeito do pâncreas para produzir insulina (50,0\%), para aqueles com até cinco anos de doença.

Tabela 3 - Distribuição dos usuários diabéticos cadastrados no SEMPRE, segundo a faixa etária, tempo e conhecimento da doença, Ribeirão Preto - São Paulo, 2005.

\begin{tabular}{|c|c|c|c|c|c|c|c|}
\hline \multirow[t]{2}{*}{$\begin{array}{l}\text { Faixa } \\
\text { etária } \\
\text { (anos) }\end{array}$} & \multirow[t]{2}{*}{$\begin{array}{c}\text { Tempo } \\
\text { de } \\
\text { diabetes }\end{array}$} & \multicolumn{2}{|c|}{$\begin{array}{c}\text { Excesso de açúcar no } \\
\text { sangue }\end{array}$} & \multicolumn{2}{|c|}{$\begin{array}{c}\text { Defeito do pâncreas } \\
\text { para produzir } \\
\text { insulina em } \\
\text { quantidades } \\
\text { adequadas }\end{array}$} & \multicolumn{2}{|c|}{$\begin{array}{c}\text { Dificuldade } \\
\text { do corpo para } \\
\text { utilizar a insulina }\end{array}$} \\
\hline & & Assinalou & $\begin{array}{c}\text { Não } \\
\text { assinalou }\end{array}$ & Assinalou & $\begin{array}{c}\text { Não } \\
\text { assinalou }\end{array}$ & Assinalou & $\begin{array}{c}\text { Não } \\
\text { assinalou }\end{array}$ \\
\hline \multirow[t]{3}{*}{$<60$} & $\begin{array}{l}\text { Até } 5 \\
\text { anos }\end{array}$ & $\begin{array}{c}1 \\
(20,0 \%)\end{array}$ & $\begin{array}{c}4 \\
(80,0 \%)\end{array}$ & $\begin{array}{c}2 \\
(40,0 \%)\end{array}$ & $\begin{array}{c}3 \\
(60,0 \%)\end{array}$ & $\begin{array}{c}3 \\
(60,0 \%)\end{array}$ & $\begin{array}{c}2 \\
(40,0 \%)\end{array}$ \\
\hline & $\geq 6$ anos & $\begin{array}{c}8 \\
(88,9 \%)\end{array}$ & $\begin{array}{c}1 \\
(11,1 \%)\end{array}$ & $\begin{array}{c}0 \\
(0 \%)\end{array}$ & $\begin{array}{c}9 \\
(100,0 \%)\end{array}$ & $\begin{array}{c}8 \\
(88,9 \%)\end{array}$ & $\begin{array}{c}1 \\
(11,1 \%)\end{array}$ \\
\hline & Total & $\begin{array}{c}9 \\
(64,3 \%)\end{array}$ & $\begin{array}{c}5 \\
(35,7 \%)\end{array}$ & $\begin{array}{c}2 \\
(14,3 \%)\end{array}$ & $\begin{array}{c}12 \\
(85,7 \%)\end{array}$ & $\begin{array}{c}11 \\
(78,6 \%)\end{array}$ & $\begin{array}{c}3 \\
(21,4 \%)\end{array}$ \\
\hline \multirow[t]{3}{*}{$>60$} & $\begin{array}{l}\text { Até } 5 \\
\text { anos }\end{array}$ & $\begin{array}{c}4 \\
(28,6 \%)\end{array}$ & $\begin{array}{c}10 \\
(71,4 \%)\end{array}$ & $\begin{array}{c}7 \\
(50,0 \%)\end{array}$ & $\begin{array}{c}7 \\
(50,0 \%)\end{array}$ & $\begin{array}{c}11 \\
(78,6 \%)\end{array}$ & $\begin{array}{c}3 \\
(21,4 \%)\end{array}$ \\
\hline & $\geq 6$ anos & $\begin{array}{c}11 \\
(31,4 \%)\end{array}$ & $\begin{array}{c}24 \\
(68,6 \%)\end{array}$ & $\begin{array}{c}16 \\
(45,7 \%)\end{array}$ & $\begin{array}{c}19 \\
(54,3 \%)\end{array}$ & $\begin{array}{c}31 \\
(88,6 \%)\end{array}$ & $\begin{array}{c}4 \\
(11,4 \%)\end{array}$ \\
\hline & Total & $\begin{array}{c}15 \\
(30,6 \%)\end{array}$ & $\begin{array}{c}34 \\
(69,4 \%)\end{array}$ & $\begin{array}{c}23 \\
(46,9 \%)\end{array}$ & $\begin{array}{c}26 \\
(53,1 \%)\end{array}$ & $\begin{array}{c}42 \\
(85,7 \%)\end{array}$ & $\begin{array}{c}7 \\
(14,3 \%)\end{array}$ \\
\hline
\end{tabular}




\subsection{Variáveis relacionadas ao consumo de adoçantes e alimentos dietéticos.}

Ao analisar o uso de adoçantes pelos usuários obteve-se que a grande maioria (92,3\%) os utilizam e apenas 5 (7,7\%) não usam. Dentre os que não usam adoçante, 3 (60,0\%) referiram que o motivo relacionou-se ao sabor, considerando-o ruim.

Quanto ao tipo de adoçante utilizado pelos usuários diabéticos, constata-se que há uma variedade deles em consumo (Tabela 4).

Tabela 4 - Adoçantes dietéticos utilizados pelos usuários diabéticos cadastrados no SEMPRE de Ribeirão Preto - São Paulo, 2005.

\begin{tabular}{lcc}
\hline Nome comercial dos adoçantes* & \multicolumn{2}{c}{ Freqüência } \\
\cline { 2 - 3 } & $\mathbf{N}$ & \% \\
\hline Zero Cal ${ }^{\circledR}$ & 37 & 61,7 \\
Adocyl ${ }^{\circledR}$ & 13 & 21,7 \\
Tal \& Qual ${ }^{*}$ & 13 & 21,7 \\
Finn ${ }^{\circledR}$ & 12 & 20,0 \\
Stevita ${ }^{\circledR}$ & 6 & 10,0 \\
Gold ${ }^{\circledR}$ & 5 & 8,3 \\
Stevia Plus $®$ & 3 & 5,0 \\
Outros & 8 & 13,3 \\
& &
\end{tabular}

Em relação às composições dos adoçantes usados, o aspartame é o edulcorante consumido por 38,3\% (23) dos usuários, a combinação de sacarina e ciclamato obteve 28,3\% (17), seguido do esteviosídio com 11,7\% (7) e o acessulfame-K com 1,7\% (1). Vinte e quatro usuários (40,0\%) não souberam informar a composição do seu adoçante.

Para certificar se o usuário conhecia a composição dos adoçantes consumidos, utilizou-se de três fontes de informações, ou seja, o nome comercial do adoçante assinalado, a composição informada e a forma de apresentação, sendo, líquido incolor, líquido leitoso e pó. Verificou-se que das 48 (100,0\%) respostas obtidas acerca da composição dos adoçantes, 30 (62,5\%) estavam 
corretas, isto é, houve concordância entre o nome do adoçante, a forma de apresentação e sua composição.

Quando se analisou a escolaridade em relação ao conhecimento da composição do adoçante, verificou-se que $37,5 \%$ dos que não conheciam a composição, tem o ensino fundamental incompleto (Tabela 5).

Tabela 5 - Distribuição dos usuários diabéticos cadastrados no SEMPRE, segundo a escolaridade e o conhecimento da composição do adoçante, Ribeirão Preto - São Paulo, 2005.

\begin{tabular}{lcc}
\hline Escolaridade & \multicolumn{2}{c}{ Não sabe a composição do adoçante } \\
\cline { 2 - 3 } & $\mathbf{N}$ & $\mathbf{\%}$ \\
\hline Alfabetizado (sem escola) & 0 & $0,0 \%$ \\
Ensino fundamental completo & 4 & 16,7 \\
Ensino fundamental incompleto & 9 & 37,5 \\
Ensino médio completo & 7 & 29,1 \\
Ensino médio incompleto & 0 & $0,0 \%$ \\
Ensino superior completo & 4 & 16,7 \\
Ensino superior incompleto & 0 & $0,0 \%$ \\
\hline Total & 24 & $100,0 \%$ \\
\hline
\end{tabular}

Cabe destacar, que 9 usuários (15,0\%) utilizam açúcar ou mel para adoçar os alimentos e/ou preparações consumidas.

No que se refere aos critérios utilizados na escolha do adoçante para a sua aquisição obteve-se que para 33 usuários diabéticos (55,0\%), os critérios estão relacionados ao sabor. Destaca-se neste estudo, a influência do nutricionista na escolha do adoçante com 16,7\% (Tabela $6)$. 
Tabela 6 - Critérios utilizados pelos usuários diabéticos cadastrados no SEMPRE, para escolha do adoçante, Ribeirão Preto - São Paulo, 2005.

\begin{tabular}{lcc}
\hline Critérios para escolha do adoçante* & \multicolumn{2}{c}{ Freqüência } \\
\cline { 2 - 3 } & $\mathbf{N}$ & $\mathbf{\%}$ \\
\hline Sabor & 33 & 55,0 \\
Por orientação de médicos & 13 & 21,7 \\
Por orientação de nutricionista & 10 & 16,7 \\
Preço & 9 & 15,0 \\
Sugestão de amigos & 7 & 11,7 \\
Propagandas em TV, rádio, revistas & 2 & 3,3 \\
Outros motivos & 2 & 3,3 \\
& & \\
\hline
\end{tabular}

* múltiplas respostas

Quanto à forma de apresentação dos adoçantes consumidos pelos usuários diabéticos temse que 50 deles (83,3\%) utilizam a forma líquida e 24 (40,0\%) em pó. Os usuários podiam assinalar o uso de ambas as formas de apresentação dos adoçantes.

Ao analisar como os usuários utilizam os adoçantes líquidos, obteve-se que 43 (87,8\%) deles contam as gotas e 4 (8,2\%) referem esguichar o líquido. Em relação aos adoçantes sob a forma pó, tem-se que 19 usuários (63,3\%) utilizam em embalagem única, ou seja, em envelope e 11 (36,7\%) preferem o uso de colheres para medir.

Ao investigar os motivos pelos quais os usuários diabéticos utilizam os adoçantes líquidos, verificou-se que para 21 (42,9\%) deles o motivo está relacionado ao costume e para os adoçantes em pó os motivos foram além do costume, à praticidade com 23,3\% para ambos os motivos (Tabela 7). 
Tabela 7 - Motivos referidos pelos usuários diabéticos cadastrados no SEMPRE, para escolha do adoçante líquido e pó, Ribeirão Preto - São Paulo, 2005.

\begin{tabular}{lcc}
\hline Adoçante líquido* $^{*}$ & \multicolumn{2}{c}{ Freqüência } \\
\cline { 2 - 3 } & $\mathbf{N}$ & $\mathbf{\%}$ \\
\hline Sempre usou e está acostumado & 21 & 42,9 \\
É mais prático & 19 & 38,8 \\
É mais fácil de encontrar fora de casa & 7 & 14,3 \\
Adoça mais & 6 & 12,2 \\
Porque ganha & 1 & 2,0 \\
Outros & 1 & 2,0 \\
Adoçante em pó* & & \\
Sempre usou e está acostumado & & 23,3 \\
É mais prático & 7 & 23,3 \\
Adoça mais & 7 & 16,7 \\
Porque ganha & 5 & 3,3 \\
Outros & 1 & 36,7 \\
\end{tabular}

* múltiplas respostas

Em relação à substituição dos adoçantes, dos 60 (100,0\%) usuários que os utilizam, 37 (62,7\%) referiram não trocar de adoçante, 22 (37,3\%) trocam e 1 não respondeu a questão. Dos $22(37,3 \%)$ que realizam a troca de adoçante, as razões para $5(22,7 \%)$ deles relacionou-se ao fato de trazer prejuízo a saúde a utilização, sempre do mesmo adoçante, 3 (13,6\%) porque enjoaram do sabor, 3 (13,6\%) por falta do adoçante em uso no supermercado quando da compra, 2 (9,1\%) pelo custo elevado e $11(47,8 \%)$ por outros motivos. Na Tabela 8 verificam-se os outros motivos alegados pelos usuários para trocar de adoçante.

Tabela 8 - Motivos referidos pelos usuários diabéticos cadastrados no Sempre, para troca do adoçante, Ribeirão Preto - São Paulo, 2005.

\begin{tabular}{lcc}
\hline Motivos para a troca de adoçantes* & N & Freqüência \\
\cline { 2 - 3 } & 3 & $\mathbf{\%}$ \\
\hline Buscar outros sabores & 3 & 27,3 \\
Foi orientada a trocar & 1 & 27,3 \\
Impedir acúmulo do princípio ativo no corpo & 1 & 9,1 \\
Variar a composição & 1 & 9,1 \\
Disponibilidade do produto & 1 & 9,1 \\
Visibilidade na prateleira & 1 & 9,1 \\
Depende da finalidade a ser usado & & 9,1 \\
\hline
\end{tabular}

* múltiplas respostas 
Cabe destacar que dos 22 (37,3\%) usuários que alternam o uso de adoçantes, 11 (52,4\%) o fazem trocando a marca do adoçante, 5 (23,8\%) trocando de edulcorante contido no adoçante, 3 (14,3\%) pela forma de apresentação do produto e 2 (9,5\%) por outra marca e forma de apresentação do adoçante.

Quanto à periodicidade para a compra do adoçante pelos usuários diabéticos, obteve-se que para $27(45,8 \%)$ deles a compra do produto é mensal, 8 (13,6\%) bimestral, 2 (3,4\%) quinzenal, 9 (15,3\%) o período para a compra do produto não obedece uma periodicidade regular e 13 (22,0\%) não lembravam da periodicidade.

Dos 60 (100,0\%) usuários que utilizam adoçantes, somente 23 (38,3\%) responderam a questão acerca do custo na compra dos mesmos. Tem-se que o custo médio foi de seis reais e oitenta e oito centavos. A soma dos gastos dos 23 usuários totalizam cento e cinqüenta e oito reais. Quase sessenta e dois por cento dos usuários não sabiam quanto gastavam com adoçantes.

No que se refere à freqüência diária do uso do adoçante verificou-se que 29 usuários diabéticos (48,3\%) utilizam duas a três vezes ao dia, 22 (36,7\%) mais de três vezes ao dia e 9 $(15,0 \%)$ somente uma vez ao dia.

Quanto aos motivos que levam os usuários a utilizar o adoçante, obteve-se que 54 (90,0\%) deles utilizam porque não podem usar o açúcar para adoçar os alimentos, 11 (18,3\%) por ordem médica e 3 (5,0\%) por gostar de alimentos doces.

Ao investigar se os usuários gostam de utilizar adoçantes, obteve-se que dos 60 (100,0\%) que os utilizam, 49 (83,1\%) gostam de usá-lo, 10 (16,9\%) não gostam e 1 não respondeu a questão. Dos 49 (100\%) que gostam de usar adoçante, 25 (51,0\%) utilizam porque julgam que o açúcar traz prejuízos para o controle do diabetes, 16 (32,7\%) deles apontam que o adoçante ajuda a melhorar o controle da doença e 6 (12,2\%) consideram o adoçante mais saudável que o açúcar. 
Em relação ao uso de adoçante fora do domicílio tem-se que 54 usuários (90,0\%) faz uso e 6 (10,0\%) não. Os lugares mais citados para uso do adoçante além do domicílio foram, restaurantes, bares, lanchonetes e padarias por 42 (76,4\%) usuários, casa de amigos e parentes por 37 (67,3\%) e no trabalho por $12(21,8 \%)$.

No que se refere à necessidade de utilização de adoçantes pela pessoa diabética, 54 (84,4\%) usuários consideram que há necessidade, 8 (12,5\%) não e 2 (3,1\%) não souberam opinar.

Segundo os dados da Tabela 9, observa-se que a maioria dos usuários que considera o uso do adoçante como uma necessidade, tem ensino fundamental incompleto, e que 23,5\% dos usuários com ensino superior completo não julgam necessário o uso do adoçante.

Tabela 9 - Distribuição dos usuários diabéticos cadastrados no SEMPRE, segundo a escolaridade e a necessidade de usar adoçante, Ribeirão Preto - São Paulo, 2005.

\begin{tabular}{|c|c|c|c|c|}
\hline \multirow[t]{3}{*}{ Escolaridade } & \multicolumn{4}{|c|}{ Necessidade de usar adoçante } \\
\hline & Sim & Não & Não sabe & Total \\
\hline & $\%$ & $\mathbf{N}$ & $\mathbf{N}$ & $\mathbf{N}$ \\
\hline Alfabetizado (sem escola) & $2(100,0)$ & $0(0,0 \%)$ & $0(0,0 \%)$ & $2(3,1)$ \\
\hline Ensino fundamental completo & $10(100,0)$ & $0(0,0 \%)$ & $0(0,0 \%)$ & $10(15,6)$ \\
\hline Ensino fundamental incompleto & $16(94,1)$ & $1(5,9)$ & $0(0,0 \%)$ & $17(26,6)$ \\
\hline Ensino médio completo & $12(80,0)$ & $3(20,0)$ & $0(0,0 \%)$ & $15(23,4)$ \\
\hline Ensino médio incompleto & $1(100,0)$ & $0(0,0 \%)$ & $0(0,0 \%)$ & $1(1,6)$ \\
\hline Ensino superior completo & $11(64,7)$ & $4(23,5)$ & $2(11,8)$ & $17(26,6)$ \\
\hline Ensino superior incompleto & $2(100,0)$ & $0(0,0 \%)$ & $0(0,0 \%)$ & $2(3,1)$ \\
\hline Total & $54(84,4)$ & $8(12,5)$ & $2(3,1)$ & $64(100,0)$ \\
\hline
\end{tabular}

Quanto ao comportamento dos usuários frente a situações onde lhes é oferecido algo para beber, obteve-se que 27 (45,0\%) deles questiona acerca da presença do açúcar. Percentual considerável de usuários (21,7\%) ignora a presença do açúcar (Tabela 10). 
Tabela 10 - Comportamento apresentado pelos usuários diabéticos cadastrados no SEMPRE, frente ao oferecimento de algo para beber, Ribeirão Preto - São Paulo, 2005.

\section{Comportamento}

\begin{tabular}{lcc}
\cline { 2 - 3 } & $\mathbf{N}$ & $\mathbf{\%}$ \\
\hline Pergunta se tem açúcar e se não tiver aceita & 27 & 45,0 \\
Recusa & 18 & 30,0 \\
Aceita sem perguntar se está adoçado & 7 & 11,7 \\
Consome o líquido adoçado com açúcar & 6 & 10,0 \\
Outros & 2 & 3,3
\end{tabular}

Ao investigar o preparo de receitas com adoçantes, obteve-se que 38 usuários (58,5\%) já realizaram alguma preparação, sendo que 31 (79,5\%) e 26 (66,7\%) deles utilizaram na elaboração de receitas de doces e bolos, respectivamente. Em relação ao sabor das receitas preparadas com adoçantes, 24 (63,2\%) diabéticos aprovaram o sabor.

Em relação ao consumo de alimentos dietéticos industrializados, tem-se que 50 (76,9\%) dos usuários os utilizam e 15 (23,1\%) não.

Na Tabela 11, relaciona-se o consumo de alimentos diet industrializados com a faixa etária dos usuários. Observa-se que a proporção dos diabéticos com idade inferior a 60 anos que consomem alimentos diet industrializados é maior do que os com idade acima de 60 anos.

Tabela 11 - Caracterização dos usuários diabéticos cadastrados no SEMPRE, segundo o consumo de alimentos diet industrializados em relação a faixa etária, Ribeirão Preto - São Paulo, 2005.

\begin{tabular}{|c|c|c|c|}
\hline \multirow[t]{3}{*}{$\begin{array}{l}\text { Faixa etária } \\
\text { (anos) }\end{array}$} & \multicolumn{2}{|c|}{$\begin{array}{c}\text { Consome alimentos diet } \\
\text { industrializados }\end{array}$} & \multirow[t]{2}{*}{ Total } \\
\hline & Não & Sim & \\
\hline & $\mathbf{N}$ & $\%$ & $\%$ \\
\hline$<\mathbf{6 0}$ & $2(14,3)$ & $12(85,7)$ & $14(21,5)$ \\
\hline$>60$ & $13(25,5)$ & $38(74,5)$ & $51(78,5)$ \\
\hline Total & $15(23,1)$ & $50(76,9)$ & $65(100,0)$ \\
\hline
\end{tabular}


Os motivos relacionados à recusa para o consumo de alimentos dietéticos industrializados podem ser visualizados na Tabela 12.

Tabela 12 - Motivos referidos pelos usuários diabéticos cadastrados no SEMPRE, relacionados a recusa para consumir alimentos dietéticos industrializados, Ribeirão Preto - São Paulo, 2005.

\begin{tabular}{lcc}
\hline Motivos & \multicolumn{2}{c}{ Freqüiência } \\
\cline { 2 - 3 } & $\mathbf{N}$ & $\mathbf{\%}$ \\
\hline Sabor ruim & 5 & 7,7 \\
Desconfiança nos produtos & 5 & 7,7 \\
Produtos caros & 4 & 6,2 \\
Não respondeu a questão & 1 & 1,5 \\
\hline
\end{tabular}

A seguir na Tabela 13, verificam-se os principais alimentos dietéticos industrializados consumidos pelos usuários diabéticos.

Tabela 13 - Alimentos dietéticos industrializados consumidos pelos usuários diabéticos cadastrados no SEMPRE, Ribeirão Preto - São Paulo, 2005.

\begin{tabular}{lcc}
\hline Alimentos diet consumidos* & \multicolumn{2}{c}{ Freqüência } \\
\cline { 2 - 3 } & $\mathbf{N}$ & $\mathbf{\%}$ \\
\hline Refrigerantes & 44 & 88,0 \\
Gelatinas & 38 & 76,0 \\
Pudins, flans & 26 & 52,0 \\
Chocolates & 21 & 42,0 \\
Geléias & 18 & 36,0 \\
Balas, chicletes & 16 & 32,0 \\
Outros & 5 & 10,0 \\
\end{tabular}

* múltiplas respostas

Quanto ao consumo de alimentos diet, a maior preferência citada foi o refrigerante seguido da gelatina diet.

Ao investigar a necessidade de consumo de alimentos dietéticos industrializados pelos diabéticos, 45 usuários (70,3\%) julgam haver necessidade, 17 (26,6\%) não e 2 (3,1\%) não souberam opinar. 
Em relação à orientação dietética como parte do tratamento do diabetes mellitus, obtevese que 63 (96,9\%) usuários receberam esta orientação, sendo que 57 (90,5\%) deles a receberam da nutricionista, 54 (85,7\%) do médico e 13 (20,6\%) do enfermeiro.

Todos os usuários reconhecem o plano alimentar como um cuidado importante no tratamento da doença. Em contrapartida, 35 (55,6\%) referem seguir o plano alimentar prescrito, 25 (39,7\%) o seguem parcialmente e 3 (4,8\%) não o seguem.

Em relação à orientação de substituir o açúcar pelo adoçante, 59 (93,7\%) dos diabéticos afirmam ter recebido esta orientação. No entanto, quanto ao uso de alimentos dietéticos, obtevese que apenas 48 (76,2\%) deles a receberam.

Ao analisar o conhecimento que os usuários diabéticos do SEMPRE tem acerca dos alimentos diet e light, verifica-se na Tabela 14, que 44 (67,7\%) deles definem o alimento diet como aquele que não contém açúcar e para 26 deles (40,6\%) o alimento light é aquele que contém menor quantidade de açúcar em comparação ao alimento convencional. 
Tabela 14 - Conceitos de alimento diet e light referidos pelos usuários diabéticos cadastrados no SEMPRE, Ribeirão Preto - São Paulo, 2005.

\begin{tabular}{lcc}
\hline Conceito de alimento diet* & \multicolumn{2}{c}{ Freqüência } \\
\cline { 2 - 3 } & $\mathbf{N}$ & $\mathbf{\%}$ \\
\hline Não tem açúcar & 44 & 67,7 \\
Indicado para diabéticos & 27 & 41,5 \\
Indicado para dietas de emagrecimento & 8 & 12,3 \\
Tem menos açúcar & 7 & 10,8 \\
Não tem gordura & 5 & 7,7 \\
Não pode ser consumido por diabéticos & 4 & 6,2 \\
Não sabe & 4 & 6,2 \\
Engorda menos & 3 & 4,6 \\
Tem menos gordura & 2 & 3,1 \\
Outro & 1 & 1,5 \\
& & \\
Conceito de alimento light* & & 40,6 \\
Tem menos açúcar & 26 & 25,0 \\
Indicado para dietas de emagrecimento & 16 & 25,0 \\
Tem menos gordura & 16 & 17,2 \\
Não tem gordura & 11 & 12,5 \\
Engorda menos & 8 & 10,9 \\
Não tem açúcar & 7 & 9,4 \\
Não sabe & 6 & 6,3 \\
Indicado para diabéticos & 4 & 4,7 \\
Não pode ser consumido por diabéticos & 3 & \\
& & \\
\hline * múltiplas respostas & & \\
& &
\end{tabular}

No que se refere à maneira como os usuários identificam o alimento diet e light durante a compra, obteve-se que a maioria 39 (62,9\%) procura pela palavra diet ou light contida na embalagem do produto (Tabela 15).

Tabela 15 - Maneiras utilizadas pelos usuários diabéticos cadastrados no SEMPRE, para identificação do alimento diet e light durante a compra, Ribeirão Preto - São Paulo, 2005.

\begin{tabular}{lcc}
\hline Identificação do alimento diet e light & \multicolumn{2}{c}{ Freqüência } \\
\cline { 2 - 3 } & $\mathbf{N}$ & $\mathbf{\%}$ \\
\hline Procura a palavra diet ou light na embalagem & 39 & 62,9 \\
Lê o rótulo/ingredientes & 31 & 50,0 \\
Verifica se tem açúcar ou não & 15 & 24,2 \\
Não sabe & 3 & 4,8 \\
Pergunta para funcionário da loja & 2 & 3,2 \\
\hline
\end{tabular}

* múltiplas respostas 
Podemos identificar que os fatores que interferem no uso de adoçantes e alimentos dietéticos para esta população são: as informações incorretas que as pessoas tem em relação a estes produtos como, pensar que fazem mal a saúde, o sabor considerado ruim e a desconfiança e custo elevado dos alimentos diet industrializados. Também a preferência pelo sabor doce, a proibição do consumo de açúcar, a orientação de profissionais para o uso de adoçantes, assim como da necessidade do uso destes produtos que muitos julgam haver. 


\section{Discussão}

O predomínio do sexo feminino encontrado neste estudo também ocorreu no estudo de Castro (1999) quando investigou o consumo de adoçantes e produtos dietéticos de um grupo de indivíduos diabéticos atendidos em um centro ambulatorial público da cidade de São Paulo, atribuindo este fato talvez a maior procura e freqüência das mulheres ao serviço de saúde.

O maior número de usuários idosos relaciona-se a organização dos grupos do programa de atendimento multiprofissional em diabetes do SEMPRE, pois a maioria deles realizam-se nos períodos da manhã e tarde onde quase a totalidade dos usuários que freqüentam tais grupos são economicamente inativos.

Quanto à escolaridade, esta é uma variável importante, à medida que a população torna-se mais esclarecida e isto poderá facilitar a compreensão e o processo de educação em diabetes. Educar em diabetes, não é apenas receber a informação, mas sim promover mudanças no estilo de vida (KRARAUER, 2004). Assim, teremos indivíduos mais preocupados com a qualidade dos alimentos consumidos, como por exemplo, a pessoa que observa na compra de alimentos, a integridade da embalagem, data de validade, faz a leitura do rótulo, verificando ingredientes e as informações nutricionais como valor calórico e teor de nutrientes.

A renda familiar para esta população investigada tem mediana elevada que pode estar relacionada ao seu perfil diferenciado quanto à escolaridade, bem como a aquisição de um plano particular de assistência à saúde, quando comparado ao estudo de Castro (1999). Assim, a renda para estes usuários pode contribuir com maior acesso a uma variedade de alimentos e conseqüentemente maior consumo.

O diabetes tipo 2 foi o tipo encontrado na maioria dos usuários. Este resultado reflete as características da população estudada, com predomínio de pessoas idosas em que o diabetes tipo 
2 é mais freqüente. Prevalência também encontrada nos estudos de Malerbi \& Franco (1992), Castro (1999), Torquato et al. (2003) e Teixeira (2003). No estudo de Castro o diabetes tipo 2 ocorreu em $87 \%$ dos casos e Teixeira encontrou 85,7 \%.

Em relação ao conhecimento do conceito de diabetes por parte dos usuários, nota-se na Tabela 2 que 71,9\% deles tem um conceito incompleto de diabetes, apesar deste conteúdo fazer parte do elenco de temas abordados pela enfermeira nos grupos do programa de atendimento multiprofissional em diabetes. Além disso, soma-se o fato de muitos deles estarem inseridos nestes grupos do SEMPRE há dois, três ou mais anos. Porém, é preciso considerar que o processo de educação é lento, gradativo e contínuo (BRASIL, 2001). O conhecimento adequado da doença pelas pessoas diabéticas torna-se necessário para a implantação das estratégias de sua prevenção, de suas complicações e tratamento adequado.

Neste estudo como também no de Castro (1999) houve predomínio do uso de adoçantes. Ramos e Storel Júnior (2001) descrevem que a participação do açúcar no mercado tem dado lugar aos adoçantes dietéticos. Fato que pode ser justificado pelo aumento da oferta de adoçantes e alimentos diet e light no mercado brasileiro, bem como pela aquisição destes produtos por pessoas diabéticas, obesas, hipertensas, dislipidêmicas e também, por aquelas que querem manter a forma física. Segundo dados da ABIAD cerca de 35\% dos lares brasileiros consomem algum tipo de produto diet ou light. (OLIVEIRA; ASSUMPÇÃO, 2000; ALIMENTOS, 2006).

As marcas comerciais mais citadas neste estudo estão de acordo com a reportagem de uma revista de circulação nacional, relacionando-as como as mais vendidas no mercado brasileiro (WEINBERG, 2006). Percebe-se com isso que os adoçantes são mais conhecidos pelo nome comercial, do que por sua composição.

No que tange as composições dos adoçantes utilizados neste estudo, houve concordância com os achados do estudo de Nakasato, Isosaki e Vieira (1999), quando analisaram os tipos de 
adoçantes consumidos por 155 pacientes seguidos em um ambulatório de nutrição de uma instituição pública da cidade de São Paulo, no qual o aspartame também foi o edulcorante mais utilizado. Em análise realizada sobre o efeito de alguns adoçantes em preparações culinárias, os adoçantes a base de aspartame foram os mais aceitos em relação ao sabor, sabor residual e pela interferência de não amargar o alimento (WEINBERG, 2006). Já Ioshii e Toledo (1994), ao verificarem o uso de produtos dietéticos de um grupo de consumidores de Curitiba-PR, o aspartame não foi o edulcorante mais consumido como o encontrado neste estudo e sim, a combinação sacarina e ciclamato seguida pelo aspartame.

Observamos que parte dos usuários investigados usam açúcar na sua alimentação. Mesmo sem a necessidade da restrição do açúcar na alimentação do diabético, para que este possa ser ingerido, ele deve ser incluído em um plano alimentar equilibrado, substituindo outras fontes de carboidratos (GOVEIA; BRUNO, 2003). Assim, se faz necessário a orientação de um profissional habilitado para fazer esta adequação.

O nutricionista exerceu maior influência na escolha do adoçante neste estudo, quando comparado a influência de 1\% encontrada por Castro (1999). Este fato pode ser justificado pela composição da equipe multiprofissional do SEMPRE, na qual a nutricionista desempenha papel de destaque nos grupos de pessoas diabéticas. Nota-se também que, para esta população, a mídia exerceu pouca influência na escolha do adoçante. Por outro lado, a contribuição da mídia talvez constitua um fator importante na divulgação dos produtos existentes no mercado, pois, no presente estudo, o sabor foi o critério mais decisivo na escolha do adoçante.

A preferência pelos adoçantes sob a forma líquida, o costume como a principal justificativa para o uso, assim como a contagem das gotas, foram também os achados do estudo de Castro (1999). 
A recomendação de alternar o uso de adoçantes para evitar possíveis efeitos cumulativos dos edulcorantes (AMERICAN DIETETIC ASSOCIATION, 2004), não é seguida por todos os usuários que usam adoçantes. No entanto, a justificativa para a troca do adoçante pela maioria dos usuários parece significar o motivo real da recomendação. Porém, quando foi investigado como era realizada a troca de adoçantes, verifica-se que a maioria dos usuários desconhece que esta deve referir-se a composição do adoçante e não somente da marca comercial do produto.

Outros autores ao investigarem a quantidade diária habitualmente consumida de adoçantes de 36 diabéticos da cidade de Pelotas-RS, encontraram que a maior freqüência de uso foi de duas vezes ao dia, como o observado neste estudo (ASSUNÇÃO; ANDERSON E CAVALCANTI, 1994).

Ao analisar os critérios de dosagem utilizados pelos usuários para o uso dos adoçantes, a freqüência diária e a periodicidade de compra, os resultados indicam um consumo diário abaixo dos limites recomendados para a maioria dos diabéticos. Outros estudos também constataram que o consumo de edulcorantes pela população está abaixo da ingestão diária aceitável (ASSUNÇÃO; ANDERSON; CAVALCANTI, 1994; NAKASATO; ISOSAKI; VIEIRA, 1999).

A maioria dos usuários julgam haver necessidade de utilização de adoçantes e alimentos dietéticos pela pessoa diabética. Estes produtos não são imprescindíveis na alimentação do diabético, mas podem auxiliar no controle glicêmico da doença, contribuir na satisfação pelo sabor doce permitindo uma melhor qualidade de vida (GOVEIA; BRUNO, 2003).

A experiência como nutricionista de participar de alguns grupos do programa de atendimento multiprofissional em diabetes do SEMPRE, permite levantar algumas dificuldades quanto à leitura dos rótulos de produtos dietéticos, tais como, o hábito ainda não consolidado por parte dos consumidores, a quantificação da porção do alimento, o tamanho muito pequeno das letras dos ingredientes e informações nutricionais, muitas vezes porque a própria embalagem é 
pequena e não comporta todas as informações necessárias ao consumidor, levando-os a buscar o serviço de atendimento ao consumidor para obtê-las. Outro ponto importante é a compreensão prejudicada da mensagem dos rótulos, por se apresentar com nomes técnicos de difícil entendimento para leigos.

Recomenda-se a leitura cuidadosa dos rótulos dos produtos dietéticos industrializados para análise de sua composição, pois alguns têm baixa quantidade de carboidratos quando comparados aos produtos convencionais e valor calórico próximo de zero. Outros, apresentam pequena ou nenhuma diferença no conteúdo de carboidratos e calorias quando comparados aos produtos convencionais. Assim, não podem ser ingeridos livremente e sim, com moderação (BRASIL, 2002).

A desconfiança nos produtos diet referida pelos usuários deve-se ao fato de não acreditarem no poder adoçante dos edulcorantes, fazendo-os pensar que tais produtos também contêm açúcar.

Quanto ao consumo de alimentos diet, houve concordância com os estudos de Castro (1999) e Ioshii e Toledo (1994), onde a maior preferência citada foi o refrigerante seguido da gelatina diet. Além destes, outro percentual expressivo da Tabela 13 são os pudins e podem estar relacionados ao menor custo destes produtos e portanto, mais facilidade de compra em comparação com os demais alimentos citados. Uma orientação importante em relação a aquisição de alimentos diet e light que contenham edulcorantes, em especial os refrigerantes devido maior consumo é a observação de quantos tipos diferentes de edulcorantes presentes na formulação. Deve-se dar preferência para os alimentos que combinem três ou mais edulcorantes na composição, pois como a maioria não traz a comunicação sobre o limite de consumo diário, produtos com maior número de edulcorantes irão conter menor quantidade de cada tipo dos mesmos. 
Observa-se na Tabela 14 que os conceitos de alimentos diet e light, bem como as indicações para os mesmos, se confundem. O menor teor de gordura e a indicação para dietas de emagrecimento relacionaram-se mais ao termo light. Para o termo diet foi mais evidenciado a ausência do açúcar e a indicação para diabéticos. Porém, a proibição do consumo para diabéticos apareceu para ambos os conceitos, refletindo com isso, a falta de entendimento dos usuários. Estes resultados estão de acordo com outros estudos, os quais constataram o desconhecimento dos consumidores em relação aos conceitos de diet e light (CAVALCANTI, 1997; PROBLEMAS..., 2005). Estes dados indicam a necessidade de orientações mais esclarecedoras por parte dos profissionais da saúde que acompanham as pessoas diabéticas.

A maioria das pessoas investigadas neste estudo dizem procurar pelas palavras diet e light no momento da compra como recurso de identificação de tais produtos. Vale ressaltar que esta conduta nem sempre levará o consumidor a acertar, pois alguns alimentos light contém açúcar e outros não. A leitura do rótulo verificando-se qual nutriente foi reduzido e informações nutricionais, além da influência nas escolhas alimentares que pode exercer, oferece maior chance para o consumidor adquirir adequadamente o produto que deseja.

O seguimento do plano alimentar está presente em pouco mais da metade dos usuários investigados neste estudo. Araújo et al. (1999) descrevem em seu estudo que menos de um terço dos diabéticos estudados seguia a dieta prescrita. Peres, Franco e Santos (2006) ao analisar o comportamento alimentar de mulheres portadoras de diabetes tipo 2, evidenciaram dificuldade no seguimento da dieta prescrita em função dos significados associados como imagem negativa, ausência de sintomas, tristeza, revolta, perda do prazer de comer e beber, da autonomia e da liberdade para se alimentar.

Nesse contexto, torna-se importante tecer algumas reflexões sobre o comportamento alimentar frente ao desafio da adesão a terapia nutricional. O comportamento alimentar é um dos 
principais componentes do estilo de vida e bastante complexo que vai além da simples ingestão de alimentos. Está relacionado com aspectos econômicos, sociais, culturais, emocionais, além da fome e do apetite (PEREZ; ROMANO, 2004).

Segundo Prochaska et al. (1997, apud ZACCARELLI, 2005) o processo de mudança de comportamento dos indivíduos se dá em cinco estágios tais como: pré-contemplação, contemplação, decisão ou preparação, ação e manutenção. No estágio de pré-contemplação a pessoa pode desconhecer os riscos de seu comportamento e não tem a intenção de mudar um comportamento de risco nos próximos seis meses. Na contemplação a pessoa tem a intenção de mudar nos próximos seis meses e por isso precisa ser incentivada para tal. Na decisão ou preparação a pessoa já tem algum plano de ação para que ocorra a mudança nos próximos trinta dias. Na ação a pessoa mudou efetivamente o comportamento por um período de até seis meses. E na manutenção, o último estágio do processo de mudança, a pessoa incorporou as mudanças desejadas por mais de seis meses. No entanto, a recaída pode ocorrer fazendo voltar a prática do comportamento de risco. Uma intervenção educativa se faz necessário em cada estágio, promovendo conscientização da necessidade de mudança e autoconfiança para enfrentar os desafios.

Assim, os conhecimentos sobre o processo de mudança de comportamento podem contribuir com profissionais de saúde, levando-os a entender os motivos de resistência e a buscar maneiras mais adequadas de abordagem a fim de melhorar a efetividade de programas de educação nutricional e alcançar a adesão ao tratamento. 


\section{Conclusões}

As conclusões serão apresentadas conforme a seqüência dos objetivos propostos para este estudo.

Em relação às características sócio-demográficas, houve predomínio de usuários do sexo feminino, idosos e casados. A maioria tem ensino superior completo e renda familiar elevada.

Encontramos que a maioria dos usuários tem diabetes tipo 2, com um tempo de diagnóstico médio de 13,9 anos. Quanto ao conhecimento acerca da doença, as respostas mais freqüentes foram, diabetes como excesso de açúcar no sangue e defeito do pâncreas para produzir quantidade adequada de insulina e apenas 11\% tem o conceito completo da doença.

Quase a totalidade dos diabéticos usam adoçantes, constatando-se um consumo maior de aspartame em relação a outros edulcorantes. Verificou-se também que parcela considerável dos usuários que usam adoçantes, não soube informar qual era o edulcorante contido no seu adoçante.

O fator que mais influenciou os usuários na escolha do adoçante foi o sabor. Também representaram percentual significativo na escolha, a orientação por médicos e nutricionistas.

A forma de apresentação líquida para os adoçantes é a mais consumida pelos usuários, devido ao costume.

Verificou-se que os diabéticos deste estudo apresentam comportamentos que indicam controle da quantidade do adoçante no momento do uso.

Encontramos que a maioria dos diabéticos que realizam a substituição dos adoçantes o fazem trocando a marca do produto sem a preocupação com o tipo de edulcorante.

O motivo mais citado pelos usuários que leva ao uso de adoçante é por não poderem usar o açúcar. 
A maioria dos usuários considera uma necessidade o uso do adoçante e alimentos dietéticos.

A utilização de adoçantes no preparo de receitas como bolos e doces, foi realizada por mais da metade dos diabéticos.

Quanto aos alimentos dietéticos industrializados, temos que a maioria dos usuários os consomem. Verificou-se também que este consumo foi maior entre os adultos ( $<60$ anos).

O refrigerante dietético é o produto dietético mais consumido pelos entrevistados, seguido pela gelatina.

Constatou-se que os diabéticos deste estudo receberam segundo eles, menos orientações quanto ao uso de alimentos dietéticos quando comparado às orientações em relação aos adoçantes.

Em relação aos conceitos de alimento diet e light investigados pelos diabéticos, temos que para 67,7\% deles, o alimento diet não contém açúcar e 40,6\% deles, definem o alimento light como aquele que contém menor quantidade de açúcar.

As palavras diet e light presentes nos rótulos de alimentos é o critério mais utilizado pelos usuários na identificação destes produtos no momento da compra. 


\section{Considerações Finais}

Os resultados do presente estudo apontam que o uso de adoçantes e alimentos dietéticos é importante para pessoas diabéticas, pois podem contribuir para o controle metabólico da doença, possibilitando melhor qualidade de vida e reinserção no convívio social, apesar de serem dispensáveis na alimentação do diabético.

As pessoas diabéticas investigadas neste estudo estão inseridas em um serviço de medicina preventiva, o qual possibilita através de equipe multiprofissional, maior conhecimento nas questões acerca do diabetes. Porém, evidenciamos ainda algumas dificuldades em relação aos adoçantes e alimentos dietéticos. O hábito de fazer a leitura dos rótulos de tais produtos minimizaria a falta de informação e as dúvidas dos usuários, além de fazê-los consumidores mais conscientes.

Nesta direção, os profissionais de saúde, em particular o nutricionista, devem buscar estratégias para alcançar orientações efetivas. As instruções dadas em grupo podem ser tão eficientes quanto as individuais e o profissional deve ser um facilitador das mudanças de comportamento, oferecendo apoio emocional, auxílio na identificação de problemas nutricionais e de estilo de vida, sugerindo novos comportamentos, facilitando a compreensão e o controle das pessoas diabéticas.

As empresas fabricantes de adoçantes e alimentos dietéticos deveriam acrescentar nos rótulos dos produtos a quantidade diária que pode ser ingerida por quilo de peso corporal de seus produtos. Outra estratégia seria disponibilizar esta informação por folheto embalado junto ao produto, para que o consumidor não precise consultar o serviço de atendimento.

Há de se considerar que a forma de aplicação do instrumento utilizada neste estudo, constituiu uma limitação, pois algumas questões ficaram sem respostas. 
Acreditamos que o presente estudo possa contribuir com informações para maiores esclarecimentos acerca do uso de adoçantes e alimentos dietéticos, auxiliando profissionais de saúde na orientação e seguimento de pessoas portadoras de doenças crônicas. 


\section{Referências}

ALIMENTOS. Revista do idec online. 2006. Disponível em < http://www.idec.org.br $>$. Acesso em: 28 jun. 2006.

AMERICAN DIABETES ASSOCIATION [ADA]. Nutrition recommendations and principles for people with diabetes mellitus. Diabetes Care, Alexandria, v. 22, p. 42-45, jan. 1999a. Suplemento 1

AMERICAN DIABETES ASSOCIATION [ADA]. Implications of the diabetes control and complications trial. Diabetes Care, Alexandria, v. 22, p. 24-26, jan. 1999b. Suplemento 1

AMERICAN DIABETES ASSOCIATION [ADA]. Implications of the united kingdom prospective diabetes study. Diabetes Care, Alexandria, v. 22, p. 27-31, jan. 1999c. Suplemento 1

AMERICAN DIABETES ASSOCIATION [ADA]. Nutrition recommendations and principles for people with diabetes mellitus (position statement). Diabetes Care, Alexandria, v. 20, 1997. Suplemento17.

AMERICAN DIABETES ASSOCIATION [ADA]. Princípios de nutrição e recomendações em diabetes. Diabetes Care, v. III, n. 2, p. 85-95, jun. 2004a.

AMERICAN DIABETES ASSOCIATION [ADA]. Diagnóstico e classificação do diabetes mellitus. Diabetes Care, v. III, n. 2, p. 54-59, jun. 2004b.

AMERICAN DIABETES ASSOCIATION [ADA]. Recomendações nutricionais para o diabetes.

Diabetes Clínica, Rio de Janeiro, v. 2, p. 143-145, 2004c. Suplemento 1

AMERICAN DIETETIC ASSOCIATION. Position of the American dietetic association: use of nutritive and nonnutritive sweeteners. Journal of the American Dietetic Association, v. 104, n. 2, p.255-75, feb. 2004.

ARAÚJO, R. B. et al. Avaliação do cuidado prestado a pacientes diabéticos em nível primário. Revista de Saúde Pública, São Paulo, v. 33, n. 1, p. 24-32, fev. 1999. 
ASSUNÇÃO, M. C. F.; ANDERSSON, G. B.; CAVALCANTI, Z. C. H. Uso de adoçantes alternativos pelos diabéticos. Jornal Brasileiro de Medicina, v. 67, n. 5/6, p. 62-69, 1994.

BERTORELLI, A.M.; CZARNOWSKI-HILL, J.V. Review of present and future use of nonnutritive sweeteners. The Diabetes Educator, Boston, v.16, n. 5, p. 415-22, 1990.

BRASIL. Secretaria de Vigilância Sanitária. Aprova o Regulamento Técnico referente a Adoçantes de mesa. Portaria $n^{0}$ 38, 13 de janeiro de 1998. Diário Oficial da União; Poder Executivo de 15 de janeiro de 1998a.

BRASIL. Secretaria de Vigilância Sanitária. Aprova o Regulamento Técnico referente a Alimentos para Fins Especiais. Portaria $n^{0}$ 29, 13 de janeiro de 1998. Diário Oficial da União; Poder Executivo de 15 de janeiro de 1998b.

BRASIL. Secretaria de Vigilância Sanitária. Aprova o Regulamento Técnico referente a Informação Nutricional Complementar. Portaria $n^{0}$ 27, 13 de janeiro de 1998. Diário Oficial da União; Poder Executivo de 16 de janeiro de 1998c.

BRASIL. Secretaria de Políticas de Saúde. Departamento de Ações Programáticas Estratégicas. Plano de reorganização da atenção à hipertensão arterial e ao diabetes mellitus. Brasília: Ministério da Saúde, 2002.

BRASIL. Instituto para o desenvolvimento da saúde. Universidade de São Paulo. Manual de Enfermagem. Brasília: Ministério da Saúde, 2001.

BURGOS, M. G. P. A. et al. Terapia nutricional enteral em pacientes diabéticos de um hospital universitário no nordeste do Brasil. Diabetes Clínica, São Paulo, v. 6, n. 6, p. 429-34, 2002.

CARUSO, L.; MENEZES, E. W. Índice glicêmico dos alimentos. Nutrire: revista da Sociedade Brasileira de Alimentação e Nutrição, São Paulo, v. 19/20, p. 49-64, 2000.

CASTRO, A. G. P.; FRANCO, L. J. Caracterização do consumo de adoçantes alternativos e produtos dietéticos por indivíduos diabéticos. Arquivos Brasileiros de Endocrinologia \& Metabologia, São Paulo, v. 46, n. 3, p. 280-87, jun. 2002. 
CASTRO, A. G. P. Caracterização do consumo de adoçantes alternativos e produtos dietéticos por indivíduos diabéticos. 1999. 76 f. Dissertação (Mestrado) - Escola Paulista de Medicina, Universidade Federal de São Paulo, São Paulo, 1999.

CAVALCANTI, M. L. F. II Reunião Anual do Instituto Adolfo Lutz - Discute Alimentos Dietéticos. Jornal do Conselho Regional de Nutricionistas - $\mathbf{3}^{\mathbf{0}}$ região, São Paulo, n. 49, p. 1215, 1997.

COSTA, A. A.; ALMEIDA NETO, J. S. Diabetes: conceito e classificação. In: COSTA, A. A.; ALMEIDA NETO, J. S. Manual de diabetes. 4. ed. São Paulo: Sarvier, 2004. cap. 1, p. 1-16.

CRAPO, P. A. Use of alternative sweeteners in diabetic diet. Diabetes Care, San Diego, v. 11, n. 2, p. 174-81, feb.1988.

DAVIDSON, M. B. Diabetes mellitus: diagnóstico e tratamento. 4. ed. Rio de Janeiro: Revinter, 2001. cap. 1, p. 1-13.

FRANCO, L. J. Epidemiologia do Diabetes Mellitus. In: LESSA, I. et al. O adulto brasileiro e as doenças da modernidade. São Paulo: Hucitec, 1998. p. 123-139.

FREIRE, M. C. M.; CANNON, G.; SHEIHAM, A. Análise das recomendações internacionais sobre o consumo de açúcares publicadas entre 1961 e 1991. Revista de Saúde Pública, São Paulo, v. 28, n. 3, p.228-237, jun. 1994.

FREITAS, S. M. L. Alimentos com alegação diet ou light. São Paulo: Atheneu, 2005.

GOVEIA, G. R.; BRUNO, L. P. C.; PASCALI, P. M. Contagem de carboidratos \& monitorização: 101 respostas. São Paulo: Preventa, 2003. 100 p.

GRUPO DE ESTUDIO DE LA DIABETES EN LA ATENCIÓN PRIMARIA DE SALUD GEDAPS. Guía para el tratamiento de la diabetes tipo 2 en la Atención Primaria. Contribuición al programa de acción de la Declaración de St. Vicente, 2000.

HARRIS, M. I. et al. Onset of niddm occurs at leost 4-7 yr before clinical diagnosis. Diabetes Care, Alexandria, v.15, n. 7, july 1992. 
HULLEY, S. B. et al. Delineando a pesquisa clínica: uma abordagem epidemiológica. 2. ed. Porto Alegre: Artmed, 2003.

IOSHII, S. H.; TOLEDO, M. C. F. Avaliação da ingestão diária potencial de edulcorantes em Curitiba. Boletim do Centro de Pesquisa e Processamento de Alimentos, Curitiba, v. 12, n. 2, p. 139-151, jul./dez. 1994.

KING, H.; AUBERT R. E.; HERMAN W. H. Global burden of diabetes, 1995-2025. Diabetes Care, v. 21, p. 1414-1431, 1998.

KRARAUER, M. Educação em diabetes e a ADIABC. In: COSTA, A. A.; ALMEIDA NETO, J. S. Manual de diabetes. 4 ed. São Paulo: Sarvier, 2004. cap. 2, p. 23-4.

LERÁRIO, A. C. Diabete Mellito: aspectos epidemiológicos. Revista da Sociedade de Cardiologia do Estado de São Paulo, São Paulo, v. 5, n. 5, p. 885-891, 1998.

MALERBI, D. A.; FRANCO, L. J. Multicenter study of the prevalence of diabetes mellitus and impaired glucose tolerance in the urban brazilian populacion aged 30-69 yr. Diabetes Care, Alexandria, v. 15, n. 11, p. 1509-1516, nov. 1992.

MANCINI, M. C. Obstáculos diagnósticos e desafios terapêuticos no paciente obeso. Arquivos Brasileiros de Endocrinologia e Metabolismo, São Paulo, v. 45, n. 6, p.584-608, dez. 2001.

MC CARTY, D.; ZIMMET P. Diabetes 1994 to 2010: Global estimates and projections.

Melbourne: International Diabetes Institute, 1994.

MONEGO, E. T. et al. Alimentos dietéticos: uma visão prática. Revista de Nutrição PUCCAMP, Campinas, v. 7, n. 1, p. 9-13, 1994.

MOURÃO, D. M. et al. Effect of sucrose and sweetener on appetite sensation and energy expenditure in normal weight and overweight subjects. Revista Brasileira de Nutrição Clínica, v. 19, n. 2, p. 47-53, 2004.

NABORS, L. O’B.; GELARDI, R. C. Alternative sweeteners: an overview. In: Alternatives Sweeteners. 2 ed. New York: Marcel Dekker, 1991. p. 1-10. 
NAKASATO, M.; ISOSAKI, M.; VIEIRA, L. P. Consumo de adoçantes dietéticos em relação à ingestão diária aceitável. Revista da Sociedade de Cardiologia do Estado de São Paulo, São Paulo, v. 9, n. 5, p. 4-16, set./out. 1999. Suplemento A

OLIVEIRA, S. P.; ASSUMPÇÃO, B. V. Alimentos dietéticos: evolução do conceito, da oferta e do consumo. Higiene Alimentar, São Paulo, v. 14, n. 76, p. 36-42, set. 2000.

PERES, D. S.; FRANCO, L. J.; SANTOS, M. A. Comportamento alimentar em mulheres portadoras de diabetes tipo 2. Revista de Saúde Pública, São Paulo, v. 40, n. 2, p. 310-317, 2006.

PEREZ, G. H.; ROMANO, B. W. Comportamento alimentar e síndrome metabólica: aspectos psicológicos. Revista da Sociedade de Cardiologia do Estado de São Paulo, São Paulo, v. 14, n. 4, p. 544-550, jul/ago. 2004.

PROBLEMAS nos supermercados. Jornal do Comércio. 2005. Disponível em < http://www.ecrbrasil.com.br/noticias>. Acesso em: 10 out. 2005.

RAMOS, P.; STOREL JÚNIOR, A. O. O açúcar e as transformações nos regimes alimentares. Cadernos de debate, Campinas, v. VIII, p 1-18, 2001.

RODRIGUES, C. Comida leve, lucros gordos. Pequenas Empresas \& Grandes Negócios, n.150, jul. 2001. Disponível em < http://www.pegn.globo.com>. Acesso em: 10 out. 2005.

ROSADO, E. L.; MONTEIRO, J. B. R., Obesidade e a substituição de macronutrientes da dieta. Revista de Nutrição, Campinas, v.14, n. 2, p. 145-152, maio/ago. 2001.

SANCHES, A. M. Diabetes mellitus como causa de aposentadoria por invalidez. Diabetes Clinica, Rio de Janeiro, v. 4, n. 3, p. 231-234, maio/jun. 2000.

SACHS, A. Diabetes mellitus. In: CUPPARI, L.; SCHOR, N. Nutrição: Nutrição clínica no adulto. São Paulo: Manole, 2002. cap. 8, p. 151-165.

SAMPAIO, H. A. C. Terapia nutricional do paciente diabético. Nutrição em Pauta, São Paulo, n. 43, p. 34-37, jul./ago. 2000. 
SÃO PAULO. Secretaria de Estado da Saúde de São Paulo. Manual de normas e recomendações para o tratamento do diabetes. São Paulo, 2001.

SOCIEDADE BRASILEIRA DE DIABETES. Consenso brasileiro sobre diabetes 2002: diagnóstico e classificação do diabetes melito e tratamento do diabetes melito tipo 2 . Rio de Janeiro: Diagraphic, 2003a.

SOCIEDADE BRASILEIRA DE DIABETES. Manual oficial de contagem de carboidratos. Rio de Janeiro: Diagraphic, 2003b.

TEIXEIRA, C. R. S. A atenção em diabetes mellitus no serviço de medicina preventiva SEMPRE: um estudo de caso. 2003. 162 f. Tese (Doutorado) - Escola de Enfermagem de Ribeirão Preto, Universidade de São Paulo, Ribeirão Preto, 2003.

THE DIABETES CONTROL AND COMPLICATIONS TRIAL RESEARCH GROUP - DCCT. The effect of intensive Treatment of diabetes on the development and progression of long-term complications in insulin-dependent diabetes mellitus. The New England Journal of Médicine, v. 329, p. 977-986, 1993.

TORQUATO, M. T. C. G. et al. Prevalência do diabetes mellitus, diminuição da tolerância à glicose e fatores de risco cardiovascular em uma população urbana adulta de Ribeirão Preto. Diabetes Clínica, Rio de Janeiro, v. 5, n. 3, p. 183, maio/jun. 2001.

UNITED KINGDOM PROSPECTIVE DIABETES STUDY GROUP - UKPDS. Intensive bloodglucose control with sulfonylureas or insulin compared with conventional treatment and risk of complications in patients with type 2 diabetes: UKPDS 33. Lancet, New York, v. 352, p. 837-53, 1998.

VIGGIANO, C. E. Proposta de pirâmide alimentar para o diabético. Nutrição em Pauta, São Paulo, n. 50, p. 46-49, set./out. 2001.

WEINBERG, M. Os testes dos adoçantes. Revista Veja, São Paulo, ed. 1940, ano 39, n. 3, p. 9899, jan. 2006.

ZACCARELLI, E. M. Modelo transteórico e curso de vida. In: FISBERG, R. M. et al. Inquéritos alimentares: métodos e bases científicos. Barueri, SP: Manole, 2005. cap. 2, p. 5370 . 


\section{Anexos}

\section{TERMO DE CONSENTIMENTO LIVRE E ESCLARECIDO}

(Decreto 93.933 de 14/01/87: Resolução 196/96)

Prezado (a) Sr. (a)

Um estudo denominado "Uso de adoçantes e alimentos dietéticos por pessoas diabéticas” está sendo desenvolvido, com o objetivo de conhecer o uso de adoçantes e alimentos dietéticos por pessoas diabéticas cadastradas neste serviço.

Para a realização deste estudo faz-se necessário entrevistar as pessoas diabéticas acompanhadas neste serviço. A sua participação caso aceite este convite, consiste em responder um questionário.

Caso você concorde em participar do estudo estará ciente que tem o direito de esclarecer todas dúvidas sobre a pesquisa e que poderá retirar seu consentimento a qualquer momento sem que isso traga prejuízo à continuidade do seu tratamento neste serviço; que as respostas fornecidas serão mantidas em sigilo e que não será identificado. Estará ciente que a respostas do questionário serão utilizadas em trabalhos e eventos científicos na área da saúde.

Tenho ciência do exposto acima e desejo contribuir com as informações necessárias para esta pesquisa.

Ribeirão Preto, de 2005.

Assinatura do Entrevistado

Gisele de Sousa

Assinatura do Pesquisador 


\section{Instrumento de coleta de dados: Uso de adoçantes e alimentos dietéticos por pessoas diabéticas}

\section{QUESTIONÁRIO}

Grupo:

Data:

Variáveis sócio-demográficas e relacionadas à doença

1. Nome:

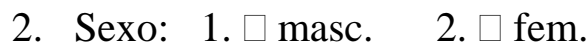

3. Data de nascimento:

4. Idade:

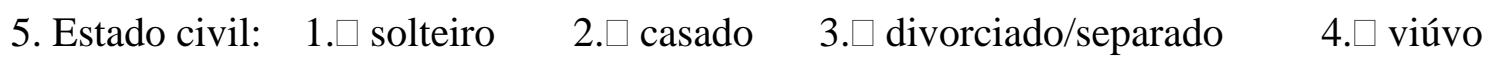

6. Escolaridade: 1. $\square$ analfabeto

2. $\square$ alfabetizado, porém nunca freqüentou a escola

3. $\square$ ensino fundamental completo ( $1^{\mathrm{a}}$ a $8^{\mathrm{a}}$ série)

4. $\square$ ensino fundamental incompleto. Qual a última série completada

5. $\square$ ensino médio completo ( $1^{\circ}$ a $3^{\circ}$ colegial)

6. $\square$ ensino médio incompleto. Qual o último ano completado

7. $\square$ ensino superior completo

8. $\square$ ensino superior incompleto

7. Qual a renda da casa? 1. quantas pessoas contribuem com essa renda: 2 . e quantas moram na casa 3.

8. Qual o seu tipo de diabetes?

1. $\square$ tipo 1

2. $\square$ tipo 2

3. $\square$ não sabe

9. Qual era sua idade quando descobriu o diabetes ?

10. O (a) Sr (a) sabe o que é diabetes?

1. $\square$ não

2. $\square \operatorname{sim} \rightarrow 2.1 \square$ excesso de açúcar no sangue

2.2 $\square$ defeito do pâncreas para produzir insulina em quantidades adequadas

2.3 $\square$ dificuldade do corpo para utilizar a insulina 


\section{Variáveis relacionadas ao consumo de adoçantes e alimentos dietéticos}

11. O (a) Sr (a) usa adoçante?

1. $\square$ não

2. $\square \operatorname{sim} \rightarrow$ passar para a questão 13

12. Porque o Sr (a) não usa adoçante?

1. $\square$ porque ouviu falar que faz mal

2. $\square$ porque acha o sabor ruim e prefere não usar

3. $\square$ porque dá trabalho preparar o alimento com e sem açúcar

4. $\square$ outros

(passar para a questão 37)

13. Qual (ais) o (s) nome (s) do (s) adoçante (s) que o Sr (a) está usando em casa?

1. $\square$ Adocyl

2. $\square$ Stevita

3. $\square$ Zero cal

4. $\square$ Gold

5. $\square$ Fin
6. $\square$ Linea

7. $\square$ Stevia plus

8. $\square$ outros/ Especificar

9. $\square$ não lembra

10. $\square$ tal \& qual

14. Qual a composição do seu adoçante ? Se assinalou mais do que um nome de adoçante na questão acima, identifique as composições que correspondem aos adoçantes.
1. $\square$ sacarina e ciclamato
5. $\square$ acessulfame $\mathrm{K}$
2. $\square$ aspartame
6. $\square$ não sabe
3. $\square$ esteviosídeo
7. $\square$ outro
4. $\square$ sucralose

15. O Sr (a) usa algum outro produto para adoçar os alimentos, como açúcar ou mel ?

1. $\square$ não $\rightarrow$ passar para a questão 17

2. $\square \operatorname{sim}$

16. Em que situações usa estes outros produtos para adoçar os alimentos ?

1. $\square$ quando acaba o adoçante

2. $\square$ quando não está em sua casa

3. $\square$ quando alguém lhe oferece algo para tomar que já vem adoçado

4. $\square$ quando está em hipoglicemia

5. $\square$ outros 
17. Como o Sr (a) escolhe o seu adoçante?

1. $\square$ preço

2. $\square$ sabor

3. $\square$ porque assistiu propagandas em TV, rádio ou revistas

4. $\square$ sugestão de amigos e parentes

5. $\square$ por orientação profissional $5.1 \square$ Médico

$5.2 \square$ Nutricionista

$5.3 \square$ Enfermeiro

$5.4 \square$ Outros

6. $\square$ outros/especificar

18. Como é o adoçante que usa em casa?

1. $\square$ líquido (incolor)

2. $\square$ líquido (cor de leite)

3. $\square$ em pó (passar para a questão 21)

19. Como o Sr (a) usa o adoçante líquido?

1. $\square$ conta as gotas

2. $\square$ "esguicha” sem contar

3. $\square$ coloca o adoçante no alimento e experimenta o sabor

4. $\square$ outros

20. Por que o Sr (a) usa adoçante líquido?

1. $\square$ porque acha que adoça mais

2. $\square$ porque sempre usou e está acostumado

3. $\square$ porque é mais fácil de encontrar fora de casa

4. $\square$ porque ganha

5. $\square$ porque é mais prático

6. $\square$ porque rende mais

7. $\square$ outros

(Após responder esta questão, e se não usar adoçante em pó, passar para a questão 23)

21. Como o Sr (a) usa o adoçante em pó?

1. $\square$ em saquinhos

2. $\square$ coloca com colher: $2.1 \square$ de café $2.2 \square$ de sobremesa $2.3 \square$ de sopa

3. $\square$ despeja o adoçante e experimenta para ver se está bom

4. $\square$ outros 
22. Por que Sr (a) usa adoçante em pó?

1. $\square$ porque acha que adoça mais

2. $\square$ porque sempre usou e está acostumado

3. $\square$ porque é mais fácil de encontrar fora de casa

4. $\square$ porque ganha

5. $\square$ porque é mais prático

6 . $\square$ porque rende mais

7. $\square$ outros

23. O Sr (a) usa sempre o mesmo adoçante?

1. $\square \operatorname{sim}$ (passar para a questão 25)

2. $\square$ não, porque $2.1 \square$ enjoou do sabor do adoçante que usava

$2.2 \square$ gostou da propaganda que ouviu no rádio ou viu na televisão ou revistas

2.3 $\square$ ouviu falar que faz mal

$2.4 \square$ preço alto

2.5 $\square$ quando foi comprar não tinha o que estava acostumado

$2.6 \square$ outros

24. Quando troca de adoçante, o Sr (a):

1. $\square$ troca de marca

2. $\square$ troca de marca e da cor do líquido

3. $\square$ troca de líquido para pó ou vice-versa

4. $\square$ troca de edulcorantes

25. Onde o Sr (a) adquire seu adoçante?

1. $\square$ ganha (passar para a questão 29)

2. $\square$ compra

26. Quem compra o adoçante que o Sr (a) utiliza?

1. $\square$ a própria pessoa

2. $\square$ alguém da família

27. Com que freqüência o Sr (a) compra o adoçante?

1. $\square$ quinzenal

2. $\square$ mensal

3. $\square$ bimestral

4. $\square$ não lembra

5. $\square$ outros

28. Quanto é gasto em média, por mês, na compra de adoçante?

29. Quantas pessoas usam o adoçante na sua casa?

1. $\square$ somente você

2. $\square 2$ a 3 pessoas

3. $\square$ mais de 3 pessoas 
30. Por que o Sr. (a) usa adoçante?

1. $\square$ gosta de alimentos doces

2. $\square$ não pode consumir açúcar

3. $\square$ o médico mandou

4. $\square$ outros

31. O Sr (a) gosta de utilizar adoçante?

1. $\square$ Não, porque? $1.1 \square$ seu gosto é ruim

$1.2 \square$ sinto-me diferente das outras pessoas que consomem açúcar

$1.3 \square$ outros

2. $\square$ Sim, porque? $2.1 \square$ acho mais saudável

2.2 $\square$ acho que açúcar faz mal para o diabetes

$2.3 \square$ ele ajuda a melhorar o diabetes

$2.4 \square$ outros

32. O Sr (a) usa adoçante em locais fora da sua casa?

1. $\square$ não

2. $\square \operatorname{sim} \rightarrow$ passar para a questão 34

33. Porque o Sr (a) não utiliza adoçantes fora de casa?

1. $\square$ não é todo lugar que tem

2. $\square$ não quero que as pessoas saibam que sou diabético

3. $\square$ não gosta de pedir para os outros

4. $\square$ outros

(passar para a questão 35)

34. Em que locais o Sr (a) utiliza o adoçante?

1. $\square$ restaurantes/ padarias/ lanchonetes/ bares

2. $\square$ casa de amigos e parentes

3. $\square$ no trabalho

4. $\square$ outros

35. Qual é a conduta do Sr(a) quando alguém lhe oferece algo para beber?

1. $\square$ pergunta se tem açúcar e se não tiver, aceita

2. $\square$ consome o líquido adoçado com açúcar

3. $\square$ recusa

4. $\square$ aceita sem perguntar se está adoçado com açúcar

5. $\square$ outros

36. Qual é a freqüência que o (a) Sr (a) usa o adoçante no dia?

1. $\square$ uma vez

2. $\square$ duas a três vezes

3. $\square$ mais de 3 vezes 
37. O Sr (a) acha que o diabético precisa usar adoçante?

1. $\square \operatorname{sim}$

2. $\square$ não

3. $\square$ não sabe

38. Em sua casa, já foi usado adoçante, no lugar do açúcar, para preparar alguma receita?

1. $\square$ não (passe para a questão 41)

2. $\square \operatorname{sim}$

39. Que tipos de receitas foram feitas?

1. $\square$ bolos

2. $\square$ receitas salgadas

3. $\square$ doces

4. $\square$ outros

40. O Sr (a) gostou destas receitas preparadas com adoçante?

1. $\square \operatorname{sim}$

2. $\square$ não

3. $\square$ mais ou menos

41. O Sr (a) consome alimentos diet industrializados?

$1 . \square$ não

2. $\square \operatorname{sim} \rightarrow$ passar para a questão 43

42. Por que o Sr (a) não usa alimentos diet?

1. $\square$ acha seu sabor ruim

2. $\square$ acha estes produtos caros

3. $\square$ não confia nestes produtos

4. $\square$ acha que eles fazem mal

(passe para a questão 44)

43. Quais são estes produtos?

1. $\square$ refrigerantes

2. $\square$ gelatinas

3. $\square$ pudins/flans

4. $\square$ chocolates

5. $\square$ balas/chicletes

6. $\square$ geléias

7. $\square$ outros

44. O Sr (a) acha que o diabético precisa utilizar estes alimentos diet?

1. $\square \operatorname{sim}$

2. $\square$ não

3. $\square$ não sabe 
45. O Sr (a) acha que a dieta é um cuidado importante no tratamento do diabetes?

1. $\square \operatorname{sim}$

2. $\square$ não

3. $\square$ não sabe

46. O Sr (a) já recebeu alguma orientação de dieta para diabetes?

1. $\square \operatorname{sim}$ ( responder as questões abaixo)

2. $\square$ não (passar para a questão 51)

47. Quem orientou essa dieta para o Sr (a)?

1. $\square$ médico

2. $\square$ nutricionista

3. $\square$ enfermeira

4. $\square$ não sabe

5. $\square$ outros

48. Nesta dieta foi recomendado ao Sr (a) substituir o açúcar pelo adoçante?

1. $\square \operatorname{sim}$

2. $\square$ não

3. $\square$ não lembra

49. Foi feita alguma orientação para o Sr (a) quanto ao consumo de alimentos diet?

1. $\square \operatorname{sim}$

2. $\square$ não

3. $\square$ não lembra

50. O Sr (a) segue atualmente essa dieta recomendada?

1. $\square \operatorname{sim}$

2. $\square$ não

3. $\square$ mais ou menos

51. O que é para o Sr (a) um alimento diet?

1. $\square$ que não tem açúcar

2. $\square$ que tem menos açúcar

3. $\square$ que engorda menos

4. $\square$ que não tem gordura

5. $\square$ que tem menos gordura

6. $\square$ que é indicado para diabéticos

7. $\square$ que é indicado para dietas de emagrecimento

8. $\square$ que não pode ser consumido por diabéticos

9. $\square$ outros

10. $\square$ não sabe 
52. O que é para o Sr (a) um alimento light?

1. $\square$ que não tem açúcar

2. $\square$ que tem menos açúcar

3. $\square$ que engorda menos

4. $\square$ que não tem gordura

5. $\square$ que tem menos gordura

6. $\square$ que é indicado para diabéticos

7. $\square$ que é indicado para dietas de emagrecimento

8. $\square$ que não pode ser consumido por diabéticos

9. $\square$ outros

10. $\square$ não sabe

53. Como o Sr(a) sabe que o alimento é diet ou light na hora da compra?

1. $\square$ vejo se tem açúcar ou não

2. $\square$ leio o rótulo/ingredientes

3. $\square$ procuro na embalagem a palavra diet ou light

4. $\square$ eu não sei

5. $\square$ pergunta para funcionária da loja

6. $\square$ outros 